\title{
CloudRoots: integration of advanced instrumental techniques and process modelling of sub-hourly and sub-kilometre land-atmosphere interactions
}

\author{
Jordi Vilà-Guerau de Arellano ${ }^{1,2}$, Patrizia Ney $^{3}$, Oscar Hartogensis ${ }^{1}$, Hugo de Boer ${ }^{4}$, Kevin van Diepen ${ }^{1}$, \\ Dzhaner Emin $^{5}$, Geiske de Groot ${ }^{1}$, Anne Klosterhalfen ${ }^{6}$, Matthias Langensiepen ${ }^{7}$, Maria Matveeva ${ }^{5}$, \\ Gabriela Miranda-García ${ }^{1}$, Arnold F. Moene ${ }^{1}$, Uwe Rascher ${ }^{5}$, Thomas Röckmann ${ }^{8}$, Getachew Adnew ${ }^{8}$, \\ Nicolas Brüggemann ${ }^{3}$, Youri Rothfuss ${ }^{3}$, and Alexander Graf ${ }^{3}$ \\ ${ }^{1}$ Meteorology and Air Quality Section, Wageningen University Research, 6708 PB Wageningen, the Netherlands \\ ${ }^{2}$ Atmospheric Chemistry Department, Max Planck Institute for Chemistry, 55128 Mainz, Germany \\ ${ }^{3}$ Institute of Bio- and Geosciences, IBG-3: Agrosphere, Forschungszentrum Jülich GmbH, 52425 Jülich, Germany \\ ${ }^{4}$ Department of Environmental Sciences, Faculty of Geosciences, Utrecht University, 3508 TA Utrecht, the Netherlands \\ ${ }^{5}$ Institute of Bio- and Geosciences, IBG-2: Plant Sciences Forschungszentrum Jülich GmbH, 52425 Jülich, Germany \\ ${ }^{6}$ Department of Forest Ecology \& Management, Swedish University of Agricultural Sciences, 90183 Umeå, Sweden \\ ${ }^{7}$ Faculty of Agriculture, University of Bonn, 53115 Bonn, Germany \\ ${ }^{8}$ Institute of Marine and Atmospheric Research Utrecht University, 3584 CC Utrecht, the Netherlands
}

Correspondence: Jordi Vilà-Guerau de Arellano (jordi.vila@wur.nl)

Received: 17 April 2020 - Discussion started: 6 May 2020

Revised: 15 July 2020 - Accepted: 20 July 2020 - Published: 31 August 2020

\begin{abstract}
The CloudRoots field experiment was designed to obtain a comprehensive observational dataset that includes soil, plant, and atmospheric variables to investigate the interaction between a heterogeneous land surface and its overlying atmospheric boundary layer at the sub-hourly and subkilometre scale. Our findings demonstrate the need to include measurements at leaf level to better understand the relations between stomatal aperture and evapotranspiration (ET) during the growing season at the diurnal scale. Based on these observations, we obtain accurate parameters for the mechanistic representation of photosynthesis and stomatal aperture. Once the new parameters are implemented, the model reproduces the stomatal leaf conductance and the leaf-level photosynthesis satisfactorily. At the canopy scale, we find a consistent diurnal pattern on the contributions of plant transpiration and soil evaporation using different measurement techniques. From highly resolved vertical profile measurements of carbon dioxide $\left(\mathrm{CO}_{2}\right)$ and other state variables, we infer a profile of the $\mathrm{CO}_{2}$ assimilation in the canopy with non-linear variations with height. Observations taken with a laser scintillometer allow us to quantify the non-steadiness of the surface
\end{abstract}

turbulent fluxes during the rapid changes driven by perturbation of photosynthetically active radiation by cloud flecks. More specifically, we find 2 min delays between the cloud radiation perturbation and ET. To study the relevance of advection and surface heterogeneity for the land-atmosphere interaction, we employ a coupled surface-atmospheric conceptual model that integrates the surface and upper-air observations made at different scales from leaf to the landscape. At the landscape scale, we calculate a composite sensible heat flux by weighting measured fluxes with two different land use categories, which is consistent with the diurnal evolution of the boundary layer depth. Using sun-induced fluorescence measurements, we also quantify the spatial variability of ET and find large variations at the sub-kilometre scale around the CloudRoots site. Our study shows that throughout the entire growing season, the wide variations in stomatal opening and photosynthesis lead to large diurnal variations of plant transpiration at the leaf, plant, canopy, and landscape scales. Integrating different advanced instrumental techniques with modelling also enables us to determine variations of ET that 
depend on the scale where the measurement were taken and on the plant growing stage.

\section{Introduction}

Evapotranspiration (ET), the net exchange of water vapour between the land and the atmosphere, remains an elusive process to be measured, quantified, and represented in models because it depends on the interaction of multiple processes that act in a wide range of scales (Katul et al., 2012). ET is a key variable in the exchange of heat, moisture, and carbon dioxide at the surface, and it strongly depends on how radiation and energy are partitioned into latent and sensible heat (Moene and Dam, 2014; Monson and Baldocchi, 2014). The amounts of direct and diffuse radiation reaching the leaves depend on the transfer of radiation that is strongly perturbed by clouds and aerosols and on its subsequent penetration into the canopy. Triggered by ambient light conditions, the stomatal responses coupled to the surface and boundary layer dynamics is the main driver that regulates how the net available radiative energy is partitioned between the turbulent sensible and latent heat fluxes (van Heerwaarden and Teuling, 2014). However, due to the highly non-stationary nature of atmospheric radiation (van Kesteren et al., 2013b) and turbulent nature of the meteorological fluctuations, we still lack a fundamental understanding of the two-way feedback between stomatal control and cloud radiation perturbations across scales and land and atmosphere conditions (Katul et al., 2012; Sikma et al., 2018).

The bidirectional link between surface processes and boundary layer clouds as described above is what we refer to as the CloudRoots concept, where boundary layer dynamics and clouds are rooted in or coupled to the surface and vice versa (Vilà-Guerau de Arellano et al., 2014). The degree of coupling depends on soil, plant, and weather conditions characterized by the diurnal variability of wind, temperature, and specific humidity (Sikma et al., 2018). To fully comprehend this system requires inclusion of all necessary parameters at the required spatial scales, from the size of the stomata (10$100 \mu \mathrm{m})$ to the depth of the boundary layer and cloud top ( $\sim 3 \mathrm{~km}$ ), as well as temporal scales from seconds to daily and seasonal cycles and across disciplines, bringing together experts from diverse fields from ecophysiology to turbulence. This can only be obtained by integrating experimental and modelling efforts. Here we describe and show the first results of the CloudRoots field experiment aimed at obtaining new understanding about the interaction between the soil, vegetation, and the clear-cloudy boundary layers at these sub-hourly and sub-kilometre scales, i.e. on spatio-temporal scales smaller than the characteristic grid resolution scales of the weather (typical resolution ranging from 1 to $10 \mathrm{~km}$ ) and climate (typical resolution ranging from 20 to $100 \mathrm{~km}$ ) models. In that respect, the CloudRoots field campaign continues the tradition of experiments that connect land surface properties with boundary layer dynamics but now instead by using advanced instrumental techniques and by modelling the coupling between the essential processes. Two examples of such previous campaigns are the First ISLSCP Field Experiment (FIFE) (Hall et al., 1989) and the Boreal EcosystemAtmosphere Study (BOREAS) (Sellers et al., 1995).

Thanks to their high-quality routine measurement programme (Franz et al., 2018; Rebmann et al., 2018), ICOS sites lend themselves as anchors for additional experiments. Here, we describe the CloudRoots campaign near the agricultural site "Selhausen" (ICOS site DE-RuS) and the Jülich Observatory for Cloud Evolution - Core Facility (JOYCE, http://joyce.cloud, last access: 21 August 2020) in Germany during spring 2018 (Löhnert et al., 2015). In order to quantify all the necessary scales of interest (leaf, canopy, and landscape), we complemented the existing radiation, flux, and soil measurements of the ICOS site by scintillometry, microlysimeters, sap flow and leaf-level flux measurements, quasi-instantaneous vertical profiles, and spectroscopic measurements of vegetation indices and sun-induced fluorescence (SIF). Scintillometers provided minute-scale turbulent fluxes enabling us to connect stomatal responses to the energy, moisture and carbon dioxide $\left(\mathrm{CO}_{2}\right)$ fluxes at this timescale. Microlysimeters, soil flux chambers, sap flow, leaf-level chambers, and canopy-resolving profiles all have the ability to distinguish vegetation from soil $\mathrm{CO}_{2}$ and water vapour $\left(\mathrm{H}_{2} \mathrm{O}\right)$ fluxes in contrast to the eddy covariance technique that provided net fluxes from the two sources combined. The remote sensing measurements of boundary layer dynamic evolution and cloud properties made at JOYCE provided evidence on diurnal variations of the boundary layer depth, the role of entrainment, and cloud diurnal variability. A key aspect of the research strategy of CloudRoots is the integration of all these measurements in a land-atmosphere conceptual model CLASS (Vilà-Guerau de Arellano et al., 2015). This model has been specially developed to support the interpretation of measurements at the sub-hourly scales (Vilà-Guerau de Arellano et al., 2019).

To this end, we study the following five facets of the diurnal interactions between the land and the atmosphere: (i) observational validation at leaf level of the mechanistic model representation of the stomatal aperture and photosynthesis, (ii) the diurnal variability of $\mathrm{H}_{2} \mathrm{O}-\mathrm{CO}_{2}$ flux partition due to the soil and plant contributions at the canopy level, (iii) the non-steadiness of these fluxes due to the influence of clouds, (iv) the spatial heterogeneity of ET inferred from the SIF measurements, and (v) the integration of the observations in the conceptual model CLASS to quantify the influence of land-surface heterogeneity and advection. We finally obtain a daily estimation of ET and discuss differences with respect to the observational or modelling techniques.

The paper is organized as follows. In Sect. 2 we give a detailed overview of the field experiment with special emphasis on the instrumentation used that serve the overall 
goals of our CloudRoots concept. The results in Sect. 3 are organized into the five topics outlined below. First, at leaf level, we validate a photosynthesis-conductance mechanistic model that is commonly used in large-eddy simulations (Pedruzo-Bagazgoitia et al., 2017; Sikma et al., 2018) and the global numerical model prediction system ECMWF-IFS (Boussetta et al., 2013). This allows us to assess the need to revisit currently used constants in the mechanistic model representing photosynthesis. This part is completed by comparing leaf transpiration rate with tiller-level measurements of sap flow at different stages of the growing season. Second, and in order to scale up to the canopy level, we analyse the soil and plant partitioning of the net ET and net ecosystem exchange (NEE) based on the inversion of observed high-resolution vertical concentration profiles (Warland and Thurtell, 2000; Santos et al., 2011). Third, in analysing the impact of clouds on ET, we measure the potential effectiveness of diffuse radiation in enhancing ET and NEE (Kanniah et al., 2012). Extending previous work by van Kesteren et al. (2013b), we quantify the time lag between fluctuations in incoming shortwave radiation and ET in the field. These real-world measurements are an essential addition to time lag of plant responses to radiation changes studied in laboratory experiments (Vico et al., 2011). Fourth, we infer the spatial variability of ET around the CloudRoots site using SIF remote sensing observations. Fifth, all of these observations are then integrated into several numerical experiments made by CLASS with special emphasis on the treatment and role of how to include surface heterogeneity and heat and moisture advection to improve the interpretation of the observations. Finally, in the discussion in Sect. 4 we bring together and discuss all CloudRoots methodologies by comparing their daily ET estimates. Conclusions are given in Sect. 5.

\section{Description of the CloudRoots field experiment and modelling effort}

\subsection{Site description}

The CloudRoots field campaign was carried out at the Terrestrial Environmental Observatory (TERENO) Selhausen, which is located in the southern part of the lower Rhine embayment in western Germany $\left(50^{\circ} 52^{\prime} 09^{\prime \prime} \mathrm{N}, 6^{\circ} 27^{\prime} 01^{\prime \prime} \mathrm{E}\right.$, $104.5 \mathrm{~m}$ altitude) in a region largely dominated by agriculture (Fig. 1). In 2011, the site was equipped with micrometeorological measurement devices for long-term monitoring of energy and carbon exchange. Since 2015, the station has been extended in accordance with ICOS standards for Level 1 sites (ICOS site code DE-RuS) (Ney et al., 2020). For this campaign, a further IRGASON eddy covariance (EC) system with an open-path gas analyser (see Sect. 2.3.7) was placed on the test field and used for additional flux measurements presented here.
The test field covered 9.8 ha and was surrounded by other croplands (Ney and Graf, 2018). As Fig. 1 shows, these cultivated areas are mainly comprised of winter wheat, winter barley, sugar beet, rapeseed, maize, potatoes, and peas, whereby the various field sizes and locations of crops has led to small-scale heterogeneity in the vegetation cover. An agricultural road, mainly used by farm machinery, passes by the northern edge of the field. The next inhabited settlement is located $500 \mathrm{~m}$ to the west (Fig. 1a). There are two lignite opencast mines in the wider surrounding of the study site, located $6 \mathrm{~km}$ northeast (extension of 4400 ha with a maximum depth of $470 \mathrm{~m}$ b.g.l.) and $6 \mathrm{~km}$ west (extension of $1400 \mathrm{ha}$ with a maximum depth of $200 \mathrm{~m}$ b.g.l.). In general, the land surface at the study site is flat and has a slope less than $4^{\circ}$. A loess layer with a thickness of about $1 \mathrm{~m}$ covers Quaternary sediments, which were mainly built up from fluvial deposits of the Rur river system. The overlying soil is an Orthic Luvisol according to the USDA classification (IUSS Working Group WRB, 2006), whose texture is silt loam with a mixture of $20 \%$ clay, $67 \%$ silt, and $13 \%$ sand.

The local climate is classified as temperate maritime with an annual mean air temperature of $10.3{ }^{\circ} \mathrm{C}$ and an annual mean precipitation of $718 \mathrm{~mm}$ (reference period 1981 2010, with data taken from the DWD climate station of the Forschungszentrum Jülich $5.3 \mathrm{~km}$ from the test site). The observation period from the beginning of May until the end of June 2018 was characterized by a $2.9^{\circ} \mathrm{C}$ higher mean air temperature $\left(17.5^{\circ} \mathrm{C}\right)$ and $46 \%$ less precipitation in comparison to the long-term average. Figure $1 \mathrm{~b}$ shows the heterogeneity quantified by the sensible heat fluxes measured at the CloudRoots site and a bare soil field nearby. In consequence and as shown by Fig. 1c, in CloudRoots we aim to integrate horizontal and vertical scales in the analysis of ET and its relation to boundary layer dynamics.

The field campaign covered the main growing phases (booting, heading, and maturity stages) of winter wheat. During the observation period, we did three intensive observation periods (IOP). During these IOPs the following complementary instruments and measurements were added: microlysimeters, leaf-level measurements, SIF measurements on canopy and regional scale, and vertical profiles of state variables and $\mathrm{CO}_{2}$ within and above the canopy were performed. Figure 2 shows a timeline of the deployment of the campaign-specific measurement setup (see Sect. 2.2 and 2.3) that includes the IOPs on 7 May (IOP 1), 15 June (IOP 2), and 28 June 2018 (IOP 3). The main meteorological and biometric conditions are summarized in Table 1 . The test field was cultivated with a crop rotation cycle typical of the region (Ney et al., 2020). The rotation prior to the observation period was beet, potatoes, and winter wheat (catch-crop) and sugar beet. Residues of the harvest of sugar beet were left on the site and ploughed in before the cultivation cycle started with the sowing of winter wheat (Triticum aestivum L.; variety Premio) in October 2017. The field was fertilized with mineral nitrogen $(\mathrm{N})$ once in March, April, and May 

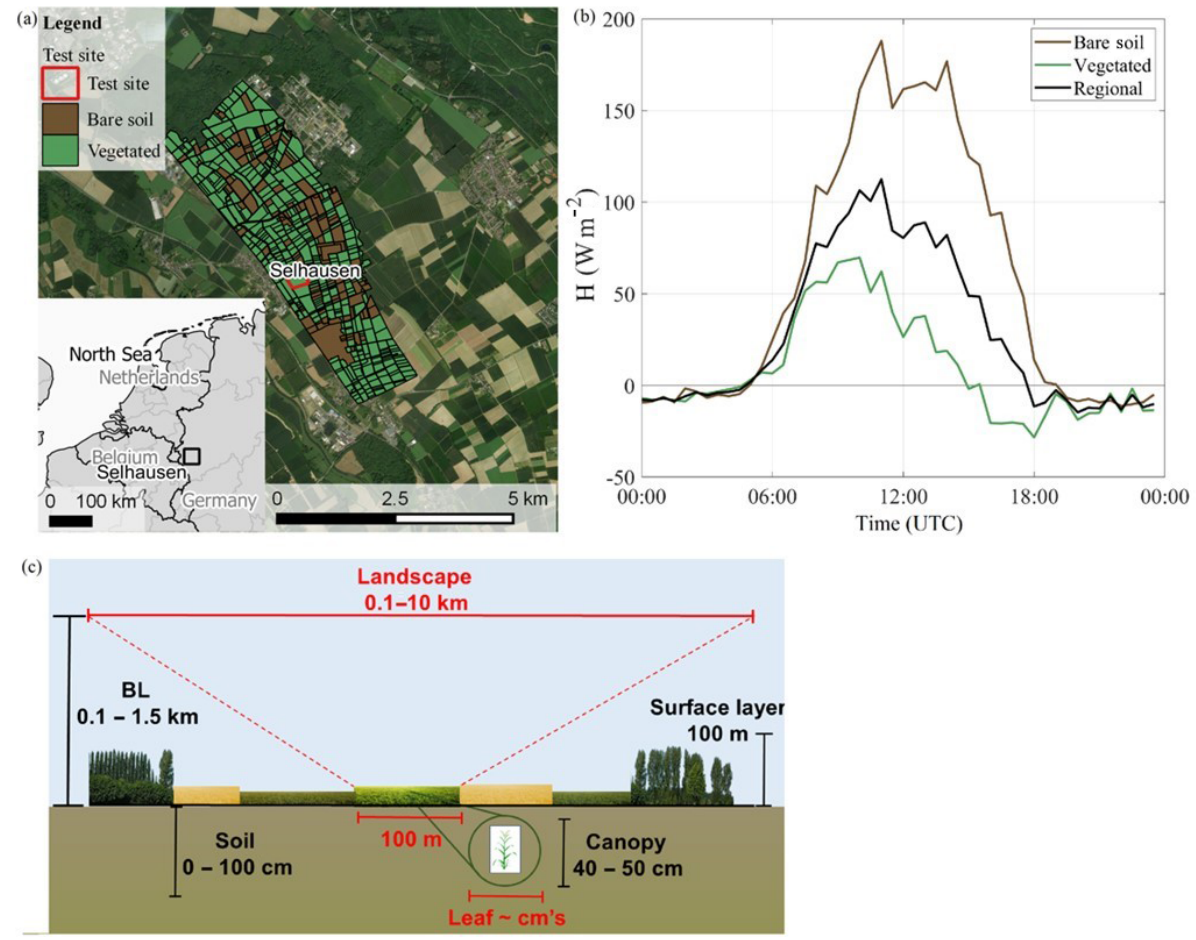

Figure 1. (a) Aerial view (Bing Maps, (c) 2019 Microsoft Corporation (C) 2019 DigitalGlobe (C) CNES (2019) Distribution Airbus DS) of the observation area. The ICOS Selhausen test site is located in the middle of the $10 \times 10 \mathrm{~km}$ map section. The surrounding agricultural area was classified into the categories bare soil (including "late crops" following Table 3) and vegetated ("early crops", forest and grassland following Table 3) during the IOP 1. (b) Corresponding sensible heat flux $(H)$ during IOP 1, whereby $H$ of bare soil and vegetated area were measured and the regional average was estimated as weighted average (60\% and $40 \%$ for vegetated and bare soil, respectively). (c) Schematic sketch of horizontal (red) and vertical (black) length scales influencing the measurements. The larger indicated horizontal and vertical scales indicate the spatial scales of boundary layer dynamics. Horizontally, the $100 \mathrm{~m}$ scale is the size of the field hosting the ICOS test site.

2018 (81.6, 39.2, and $50 \mathrm{~kg} \mathrm{~N} \mathrm{ha}^{-1}$, respectively). The wheat was harvested on 17 July 2018 with a yield of $92 \mathrm{dt} \mathrm{ha}^{-1}$. A detailed overview of the field management practices before, during, and after the campaign is given in the Appendix (Table A1).

\subsection{Weather and crop description during the IOPs}

The weather situation during all three IOPs was mainly characterized by an anticyclonic pressure pattern over central Europe (IOP 1 and IOP 2), extending up to northern Europe during IOP 3 , which led to high $2 \mathrm{~m}$ temperatures up to 24 to $26^{\circ} \mathrm{C}$ during IOP 1 and IOP 2 and $28^{\circ} \mathrm{C}$ during IOP 3 (Table 1). Cloudiness and temperature inversion heights at the top of the atmospheric boundary layer were different. While weak subsidence motions during IOP 1 led to a slightly rising temperature inversion layer between 1200 and $2000 \mathrm{~m}$ above ground level (a.g.l.) with clear conditions during the whole period (mean daytime global radiation $S \downarrow$ of $514 \mathrm{~W} \mathrm{~m}^{-2}$ ), a weak cold front passed the measuring site from the northwest in the early morning of IOP 2 (mean daytime $S \downarrow$ of $311 \mathrm{~W} \mathrm{~m}^{-2}$ ). Diurnal heating caused the replacement of a layer of stratocumulus at a height of $1800 \mathrm{~m}$ a.g.l. in the morning, followed by the appearance of scattered towering cumulus clouds. Light showers occurred only in the vicinity of the site. During IOP 3, a few shallow cumulus and cirrus clouds appeared, despite the existence of a small upper-air low that passed the area around the edge of a larger cut-off, although it was located above southeastern Europe. The mixed boundary layer was topped at a height of around $1700 \mathrm{~m}$ a.g.l.

The persistent high-pressure weather conditions resulted in a drought during the entire observation period. Ongoing dryness led to a reduction in the soil water content at $20 \mathrm{~cm}$ depth (Table 1) from $27 \mathrm{vol} \%$ during IOP 1 to $15 \mathrm{vol} \%$ at IOP 3. Maturity occurred $14 \mathrm{~d}$ earlier than in previous years. The leaf area index (LAI) ranged from $4.5 \mathrm{~m}^{2} \mathrm{~m}^{-2}$ (green growing stage) in IOP 1 to $5.5 \mathrm{~m}^{2} \mathrm{~m}^{-2}$ in IOP 2 (green/yellow ripening stage). No changes in LAI were observed between IOP 2 and IOP 3 (yellow senescence stage).

\subsection{Instrument description}

Table 2 summarizes all the variables measured and modelled during CloudRoots, together with specific nomenclature and information on units and scales. 


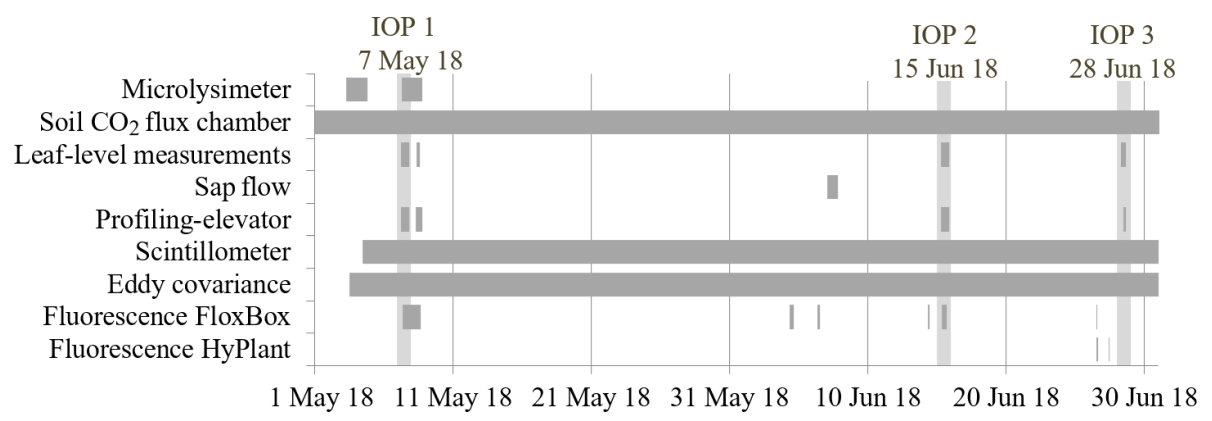

Figure 2. Campaign-specific measurement setup and temporal developments from May to June 2018, including three intensive operation periods (IOP).

Table 1. Meteorological and biometric conditions during the intensive operation periods on 7 May (IOP 1), 15 June (IOP 2), and 28 June 2018 (IOP 3). Global radiation, water vapour-pressure deficit (VPD), photosynthetically active radiation (PAR), and soil water content (SWC) are daily averages. The meteorological variables were measured at the height $2.4 \pm 0.1 \mathrm{~m}$ (see Sect. 2.3.7 for details).

\begin{tabular}{|c|c|c|c|}
\hline & IOP 1 & IOP 2 & IOP 3 \\
\hline \multicolumn{4}{|l|}{ Meteorological conditions } \\
\hline Cloud cover (okta; full cloud cover: 8) & $0-1$ & $3-6$ & $0-4$ \\
\hline Temperature range $\left({ }^{\circ} \mathrm{C}\right)$ & $7.0-25.4$ & $13.2-23.9$ & $10.1-27.6$ \\
\hline Wind range $\left(\mathrm{m} \mathrm{s}^{-1}\right)$ & $0.1-2.1$ & $0.06-1.5$ & $0.2-3.3$ \\
\hline Global radiation* $\left(\mathrm{W} \mathrm{m}^{-2}\right)$ & 514 & 311 & 462 \\
\hline \multicolumn{4}{|l|}{ Biometric conditions } \\
\hline Canopy height (m) & 0.45 & 0.80 & 0.78 \\
\hline $\operatorname{LAI}\left(\mathrm{m}^{2} \mathrm{~m}^{-2}\right)$ & 4.5 & 5.5 & 5.5 \\
\hline VPD / VPD $\max (\mathrm{hPa})$ & $11.7 / 20.9$ & $7.6 / 14.9$ & $16.0 / 23.6$ \\
\hline $\mathrm{PAR}^{*}\left(\mu \mathrm{molm} \mathrm{m}^{-2} \mathrm{~s}^{-1}\right)$ & 768 & 475 & 741 \\
\hline SWC 5, 20, $50 \mathrm{~cm}(\operatorname{vol} \%)$ & $0.20 / 0.27 / 0.30$ & $0.17 / 0.19 / 0.22$ & $0.12 / 0.15 / 0.21$ \\
\hline
\end{tabular}

* Daily averages calculated from sunrise to sunset.

\subsubsection{Microlysimeters}

For direct measurements of soil evaporation $\left(E_{\text {lys }}\right)$, four microlysimeters were installed at a number of locations around the EC-station (one in each cardinal direction) at the beginning of every observation period. In order to obtain an undisturbed soil monolith for each microlysimeter, an SDR35 polyvinyl chloride (PVC) collar with an inner diameter of $0.2 \mathrm{~m}$, a wall thickness of $0.005 \mathrm{~m}$, and a depth of $0.11 \mathrm{~m}$ was pushed carefully into the ground. Afterwards the collar including the soil column was retrieved, its outside was cleaned, and the bottom of each lysimeter was sealed with an acrylic glass disc, which prevented percolation and capillary rise from or into the microlysimeter. The microlysimeters were then weighed initially and returned to their original positions. We made sure that the lysimeters were levelled with the soil surface, their walls were fully surrounded by soil, and that the crop was affected and destroyed as little as possible, so that the general conditions and characteristics of the field site could still be maintained (e.g., regarding heat flux, shading). All four microlysimeters were subsequently collected, cleaned, weighed, and distributed again every 60 or $90 \mathrm{~min}$. A scale with a precision of $0.1 \mathrm{~g}$ (equivalent to $0.00318 \mathrm{~mm}$ evaporation) was used. The scale was enclosed in a box to avoid wind effects during the measurements. Finally, the measured weight differences were converted to the standard units of the surface energy balance $\left(\mathrm{W} \mathrm{m}^{-2}\right)$ by means of the lysimeters surface area, the time periods between weighing, and the latent heat of vaporization (Quade et al., 2019).

\subsubsection{Soil $\mathrm{CO}_{2}$ flux chambers}

Soil respiration $\left(R_{\mathrm{S}}\right)$ was observed with an automated soil $\mathrm{CO}_{2}$ gas flux system (Li-8100, Li-Cor Inc. Biosciences, Lincoln, Nebraska, USA), connected to four long-term soil flux chambers. The chambers were installed close to the ECstation (one in each cardinal direction) on top of PVC soil collars with a diameter of $0.2 \mathrm{~m}$ and a total height of $0.07 \mathrm{~m}$, from which $0.05 \mathrm{~m}$ was inserted into the soil. Each chamber was closed at $30 \mathrm{~min}$ intervals for $90 \mathrm{~s}$ during flux measurements, while $\mathrm{CO}_{2}$, water vapour concentration, and cham- 
Table 2. List of symbols, description, units, and the representative scale.

\begin{tabular}{|c|c|c|c|}
\hline Symbol & Description & Unit & Scale represented \\
\hline$A$ & photosynthesis rate & $\mu \mathrm{mol} \mathrm{m}{ }^{-2} \mathrm{~s}^{-1}, \mathrm{mg} \mathrm{m}^{-2} \mathrm{~s}^{-1}$ & landscape \\
\hline$A_{\text {leaf }}$ & leaf-level photosynthesis rate & $\mu \mathrm{mol} \mathrm{m}{ }^{-2} \mathrm{~s}^{-1}, \mathrm{mg} \mathrm{m}^{-2} \mathrm{~s}^{-1}$ & leaf \\
\hline$A_{\mathrm{m}}$ & maximum light-saturated photosynthesis & $\mu \mathrm{mol} \mathrm{m}{ }^{-2} \mathrm{~s}^{-1}, \mathrm{mg} \mathrm{m}^{-2} \mathrm{~s}^{-1}$ & landscape \\
\hline$A_{\mathrm{m}, \max 298}$ & maximum leaf-level photosynthesis rate & $\mu \mathrm{mol} \mathrm{m}{ }^{-2} \mathrm{~s}^{-1}, \mathrm{mg} \mathrm{m}^{-2} \mathrm{~s}^{-1}$ & leaf \\
\hline$E$ & evaporation & $\mathrm{mm}, \mathrm{W} \mathrm{m}^{-2}$ & several \\
\hline$E_{\text {lysi }}$ & evaporation from microlysimeters & $\mathrm{W} \mathrm{m}^{-2}$ & landscape \\
\hline$E_{\mathrm{p}}$ & evaporation profile based & $\mathrm{W} \mathrm{m}^{-2}$ & leaf \\
\hline$E_{\text {sap }}$ & sap flow & $\mu \mathrm{mol}$ tiller $^{-2} \mathrm{~s}^{-1}$ & leaf \\
\hline ET & evapotranspiration & $\mathrm{mm}, \mathrm{W} \mathrm{m}^{-2}$ & several \\
\hline $\mathrm{ET}_{\mathrm{ec}}$ & evapotranspiration eddy-covariance & $\mathrm{W} \mathrm{m}^{-2}$ & canopy \\
\hline$g_{\mathrm{sw}}$ & stomatal conductance of water vapour & $\mathrm{mol} \mathrm{m}^{-2} \mathrm{~s}^{-1}$ & leaf \\
\hline$S \downarrow$ & global radiation & $\mathrm{W} \mathrm{m}^{-2}$ & landscape \\
\hline$h$ & height & $\mathrm{m}$ & boundary layer \\
\hline$h_{\mathrm{c}}$ & landscape & $\mathrm{m}$ & canopy \\
\hline$L$ & Obukove lenght & $\mathrm{m}$ & canopy \\
\hline$L_{\mathrm{V}} E$ & latent heat flux & $\mathrm{W} \mathrm{m}^{-2}$ & several \\
\hline LAD & leaf area density & $\mathrm{m}^{2} \mathrm{~m}^{-3}$ & canopy \\
\hline LAI & leaf area index & $\mathrm{m}^{2} \mathrm{~m}^{-2}$ & canopy \\
\hline NEE & net ecosystem exchange & $\mu \mathrm{mol} \mathrm{m}{ }^{-2} \mathrm{~s}^{-1}, \mathrm{mg} \mathrm{m}^{-2} \mathrm{~s}^{-1}$ & canopy \\
\hline $\mathrm{NEE}_{\mathrm{ec}}$ & net ecosystem exchange eddy covariance & $\mu \mathrm{mol} \mathrm{m}{ }^{-2} \mathrm{~s}^{-1}, \mathrm{mg} \mathrm{m}^{-2} \mathrm{~s}^{-1}$ & canopy \\
\hline NPP / NPP canopy & net primary production & $\mu \mathrm{mol} \mathrm{m}{ }^{-2} \mathrm{~s}^{-1}, \mathrm{mg} \mathrm{m}^{-2} \mathrm{~s}^{-1}$ & canopy \\
\hline $\mathrm{NPP}_{\mathrm{p}}$ & net primary prodyuction inferres profile & $\mu \mathrm{mol} \mathrm{m}{ }^{-2} \mathrm{~s}^{-1}, \mathrm{mg} \mathrm{m}^{-2} \mathrm{~s}^{-1}$ & canopy \\
\hline PAR & photosynthetically active radiation & $\mu \mathrm{mol} \mathrm{m}{ }^{-2} \mathrm{~s}^{-1}, \mathrm{~W} \mathrm{~m}^{-2}$ & leaf/canopy \\
\hline$Q^{*}$ & net radiation & $\mathrm{W} \mathrm{m}^{-2}$ & leaf/canopy \\
\hline$R_{\mathrm{d}}$ & $\mathrm{CO}_{2}$ dark respiration & $\mathrm{mg} \mathrm{m}^{2} \mathrm{~s}^{-1}$ & landscape \\
\hline$R_{\mathrm{S}}$ & soil respiration & $\mu \mathrm{mol} \mathrm{m}{ }^{-2} \mathrm{~s}^{-1}$ & landscape \\
\hline$R_{\mathrm{S}, \mathrm{ch}}$ & soil respiration measured by chamber & $\mu \mathrm{mol} \mathrm{m}{ }^{-2} \mathrm{~s}^{-1}$ & landscape \\
\hline$R_{\mathrm{S}, \mathrm{p}}$ & soil respiration inferred from profile & $\mu \mathrm{mol} \mathrm{m}{ }^{-2} \mathrm{~s}^{-1}$ & landscape \\
\hline$H$ & sensible heat flux & $\mathrm{W} \mathrm{m}-2$ & canopy/landscape \\
\hline$T$ & temperature & ${ }^{\circ} \mathrm{C}, \mathrm{K}$ & several \\
\hline$T_{\text {air }}$ & air temperature & ${ }^{\circ} \mathrm{C}, \mathrm{K}$ & landscape \\
\hline$T_{\text {air,p }}$ & air temperature from vertical profile meas. & ${ }^{\circ} \mathrm{C}, \mathrm{K}$ & leaf/canopy \\
\hline $\operatorname{Tr}_{p}$ & transpiration, profile-based & $\mathrm{W} \mathrm{m}^{-2}$ & leaf/canopy \\
\hline$u^{r}$ & wind speed & $\mathrm{ms}^{-1}$ & landscape \\
\hline$u_{\mathrm{p}}$ & wind speed from vertical profile meas. & $\mathrm{ms}^{-1}$ & landscape \\
\hline$u_{*}$ & friction velocity & $\mathrm{m} \mathrm{s}^{-1}$ & landscape \\
\hline VPD & water vapour-pressure deficit & $\mathrm{kPa}$ & leaf/canopy \\
\hline$\alpha$ & light use efficiency & $\mathrm{mg} \mathrm{J}^{-1}$ & landscape \\
\hline$\alpha_{0}$ & initial value of light-use efficiency & $\mathrm{mg} \mathrm{J}^{-1}$ & landscape \\
\hline$\chi \mathrm{H}_{2} \mathrm{O}$ & mole fractions of $\mathrm{H}_{2} \mathrm{O}$ concentration & $\mu \mathrm{mol} \mathrm{mol}-1$ & leaf/canopy \\
\hline$\chi \mathrm{CO}_{2}$ & mole fractions of $\mathrm{CO}_{2}$ concentration & $\mu \mathrm{mol} \mathrm{mol}-1$ & leaf/canopy \\
\hline
\end{tabular}

ber headspace temperature were recorded at a sampling rate of $1 \mathrm{~Hz}$. The $\mathrm{CO}_{2}$ concentration was standardized to dry air and a constant temperature to eliminate effects of changes in air density and water vapour dilution during closure time. $R_{\mathrm{S}}$ was subsequently calculated by adjusting a linear regression fit to the final $60 \mathrm{~s}$ of the measurement before reopening.

\subsubsection{Leaf-level measurements}

Leaf gas exchange was measured using a Li-Cor LI-6400XT portable photosynthesis system with a 6400-02B LED light source. Leaf-level measurements included instantaneous stomatal conductance to water vapour $\left(g_{\text {sw }}\right)$ and photosynthesis $\left(A_{\text {leaf }}\right)$, maximum light-saturated photosynthesis $\left(A_{\max }\right)$ is the maximal primary productivity under high light conditions, $\mathrm{CO}_{2}$-response curves, and light-response 
curves. Measurements of $g_{\mathrm{sw}}$ and $A_{\text {leaf }}$ were performed during the three IOPs, starting at sunrise and ending when measurements of $g_{\mathrm{sw}}$ indicated that stomata had nearly closed $\left(g_{\mathrm{sw}}<0.05 \mathrm{~mol} \mathrm{~m}^{-2} \mathrm{~s}^{-1}\right)$. For measurements of $g_{\mathrm{sw}}$ and $A_{\text {leaf }}$, tillers were picked randomly in the field and immediately mounted in the leaf chamber for measurements. Initial tests showed no difference in $g_{\mathrm{sw}}$ between excised and attached tillers. Settings of leaf chamber photosynthetically active radiation (PAR) and $\mathrm{CO}_{2}$ followed the diurnal variability measured in the field. For comparison with other observations, measurements of $g_{\mathrm{sw}}$ and $A_{\text {leaf }}$ were binned and averaged at $30 \mathrm{~min}$ intervals. $A_{\max }$ was measured during the three IOPs, as well as on 8 May between 10:00 and 12:00 UTC. For measurements of $A_{\max }$, the light intensity (PAR) was set to $1500 \mu \mathrm{mol} \mathrm{m}^{-2} \mathrm{~s}^{-1}$ and the leaf was equilibrated under a reference $\mathrm{CO}_{2}$ concentration of $450 \mu \mathrm{mol} \mathrm{CO} \mathrm{mol}^{-1}$ air. $\mathrm{CO}_{2}$ response curves were measured during IOP 1 and IOP 3 , prescribing $\mathrm{CO}_{2}$ concentrations in the following order: 0,50 , $100,150,250,350,450,600,800$, and $1200 \mu \mathrm{molCO}_{2} \mathrm{~mol}^{-1}$ air. All $\mathrm{CO}_{2}$-response curves were measured using a light intensity (PAR) of $1500 \mu \mathrm{mol} \mathrm{m}{ }^{-2} \mathrm{~s}^{-1}$. Light-response curves were measured on IOP 1 only and used a reference $\mathrm{CO}_{2}$ concentration of $450 \mu \mathrm{mol} \mathrm{CO}_{2} \mathrm{~mol}^{-1}$ air. PAR values were changed in the following order: $0,25,50,100,200,400,800$, 1200 , and $1500 \mu \mathrm{mol} \mathrm{m}^{-2} \mathrm{~s}^{-1}$. The stomatal conductance to water vapour $\left(g_{\mathrm{sw}} \mathrm{mol} \mathrm{m}^{-2} \mathrm{~s}^{-1}\right)$ of the curves that relate $A$ and PAR (A-PAR) in between 0 and $200 \mu \mathrm{mol} \mathrm{m}^{-2} \mathrm{~s}^{-1}$ for the three repetitive experiments within the PAR range were (average and standard deviation in brackets): 0.49 (0.13), $0.12(0.02)$, and $0.34(0.06)$. Leaves were allowed to equilibrate to leaf chamber conditions in terms of gas exchange (approximately 1-2 min) but not in terms of stomatal aperture. For all measurements, leaf chamber temperature was set between 20 and $25^{\circ} \mathrm{C}$. Relative humidity in the leaf chamber was set between $60 \%$ and $75 \%$. Measurements of $A_{\max }$, $\mathrm{CO}_{2}$-response curves and light-response curves were performed on attached tillers.

\subsubsection{Sap flow}

Sap flow in wheat tillers was measured with the heat balance method (Sakuratani 1981; Baker and van Bavel, 1987). A total of 24 tillers were selected at random, diameters measured with an electronic calliper, and SGA3-type sap-flow sensors installed at the lowest possible internodes following the procedure recommended by the manufacturer (Dynamax, 2007, 2017). Sensors were connected with electrically shielded wire to AM 16/32 multiplexers controlled and scanned by CR1000 data loggers (Campbell Scientific, Logan, Utah, USA). Energy supply to the stem heaters was carefully regulated to the highest permissible level in order to obtain a strong heat signal. We employed the dual voltage regulators (Dynamax AVRDC) which were parts of wired measurement, control, and extension units assembled and tested by the heat balance sensor manufacturer (Flow32 1K A and
B models, Dynamax Inc., Houston, Texas, USA). Data were processed according to the calculation procedure of Dynamax (2007) with adaptations to wheat (Langensiepen et al., 2014) to obtain reliable data on the convective stem heat flow generated by sap flow. Here we take the evolution of the tiller densities from 480 tillers per square metre (IOP 1 and IOP 2) to 370 tillers per square metre (IOP 3 ) into account.

\subsubsection{Profiling elevator}

Vertical profiles $\mathrm{H}_{2} \mathrm{O}$ and $\mathrm{CO}_{2}$ expressed as mole fractions $\chi \mathrm{H}_{2} \mathrm{O}$ and $\chi \mathrm{CO}_{2}$ (mole of substance per mole of moist air), temperature $\left(T_{\text {air, }}\right)$ and wind speed $\left(u_{\mathrm{p}}\right)$ from the soil surface to the surface layer above the crop canopy were measured with a portable elevator system. The elevator moved continuously up and down the measuring sensors attached to an extension arm over a total profile height of $2 \mathrm{~m}$. A sampling tube connected to a differential gas analyser (LI-7000, Li-Cor Inc. Biosciences, Lincoln, Nebraska, USA) collected $\chi \mathrm{H}_{2} \mathrm{O}$ and $\chi \mathrm{CO}_{2}$ at a frequency of $20 \mathrm{~Hz}$. $T_{\mathrm{air}, \mathrm{p}}$ and $u_{\mathrm{p}}$ were measured at the same frequency by a ventilated fine-wire thermocouple (FW3, Campbell Scientific, Logan, Utah, USA) and a hot-wire anemometer (8455-075-1, TSI, Shoreview, Minnesota, USA). All measurements were duplicated as a continuous fixed-height measurement at the top of the profile. During the data post-processing, the temporal and vertical resolution of the mean profiles was set to a time-averaging block of $30 \mathrm{~min}$ with a vertical resolution of $0.025 \mathrm{~m}$. Time delays in each variable with respect to the position caused by response times of the sensors, electronic delays, and the tube transport of the gas samples were adjusted by a hysteresis minimization algorithm. Detailed information on the profile measurement setup and the processing of the data profile is given in Ney and Graf (2018). The measured concentration profiles were then used to determine the vertical source profiles of $\mathrm{H}_{2} \mathrm{O}$ and $\mathrm{CO}_{2}$, with the aim of providing an independent, non-invasive partitioning between above-ground net primary production (NPP) and $R_{\mathrm{S}}$ or evaporation $(E)$ and transpiration $\left(T r_{p}\right)$. To estimate source profiles and flux partitioning, we used an analytical dispersion Lagrangian technique introduced by Warland and Thurtell (2000) and further developed by Santos et al. (2011). Other than in the above-mentioned literature, a simple optimization method (Nelder and Mead, 1965) was used to fit four parameters: soil source, canopy source, and shape parameters $p$ and $q$ of a beta distribution, which describes the vertical source distribution within the canopy.

\subsubsection{Scintillometer}

The receiver of a displaced-beam laser scintillometer, hereafter referred to as DBLS (SLS-20, Scintec, Rottenburg, Germany), was placed $9 \mathrm{~m}$ southeast of the EC station (Fig. 1). The scintillometer measurements height was $1.95 \mathrm{~m}$ a.g.l. The path length towards the instrument transmitter was 
$86.8 \mathrm{~m}$. It was pointed along a transect from northwest to southeast. The DBLS measures the scintillation intensity of two displaced laser beams (wavelength of $670 \mathrm{~nm}$ and separation distance of $\sim 2.7 \mathrm{~mm}$ ). The structure parameter of temperature $\left(C_{T}^{2}\right)$ and dissipation rate of turbulent kinetic energy $(\varepsilon)$ are determined from the log variance of one beam and $\log$ covariance between the beams. The general equation that links the scintillometer measurements to fluxes is given by

$$
F_{x}=\rho K_{x}\left(u_{*}, \frac{z}{L}\right) z^{\frac{1}{3}} \sqrt{C_{x^{2}}^{2}},
$$

where $F_{x}$ is defined as the turbulent flux of the transported variable $x, C_{x}^{2}$ is the structure function parameter of $x$, and $K_{x}$ represents the turbulent exchange coefficient that links $F_{x}$ to $C_{x}^{2} . K_{x}$ is a function of the friction velocity, $\mathrm{u}_{*}$, and the Obukhov length, $L$. Finally, $\rho$ is the air density, and $z$ is the measurement height above the surface. For the sensible heat flux $H=F_{T}, x$ represents temperature $(T)$ and appropriate constants need to be added to convert Eq. (1) to energy fluxes. $H, u_{*}$, and $L$ are solved iteratively as a function of the DBLS-measured $C_{T}^{2}$ and $\varepsilon$ (Thiermann, 1992; Hartogensis et al., 2002). The Monin-Obukhov Similarity Theory (MOST) functions that define $K_{x}$ were taken from Kooijmans and Hartogensis (2015). For our purpose, however, the exact shape of the MOST functions is of minor importance as we are primarily interested in the dynamic temporal behaviour of the fluxes rather than an accurate description of their quantitative values. We are aware that advective contributions can lead to the violation of MOST. However, advection did not influence our measurements for two reasons. First, the scintillometer transmitter and receiver are far enough from the edges of the CloudRoots field given the height of the sensor $(1.95 \mathrm{~m})$, the wind speed and direction during the IOPs, and the stability conditions. All of these mean that the footprints are small enough to fit within the field. The typical footprint length $(90 \%$ footprint contribution) for the 3 IOPs yields IOP $1(85 \mathrm{~m})$, IOP $2(30 \mathrm{~m})$, and IOP $3(75 \mathrm{~m})$. Second, the scintillometer has a path weighting function that is at its maximum in the middle of the path and near-zero at the transmitter and receiver positions, i.e. the major contribution occurs at the farthest point of the field edge.

The added value of DBLS fluxes over the traditional EC method is that they converge to statistically stable flux estimates at much shorter flux averaging times of 1 min or less, while the EC technique typically requires flux averaging times of 10 to $30 \mathrm{~min}$ (Hartogensis et al 2002; van Kesteren et al., 2013b). The essence behind this is that the flux estimate is based on structure parameters that are defined in the inertial range of the turbulent spectrum. As such, the flux estimates rely on a limited range of the turbulent scales that contribute to the flux rather than all of them as is the case with the EC method.
We also adopted the combination technique introduced by van Kesteren et al. (2013a, b) to obtain fluxes of $\mathrm{H}_{2} \mathrm{O}$ and $\mathrm{CO}_{2}$ at these short timescales. This technique combines structure parameters of $\mathrm{H}_{2} \mathrm{O}$ and $\mathrm{CO}_{2}$ that are obtained from $\mathrm{H}_{2} \mathrm{O}$ and $\mathrm{CO}_{2}$ time series from an Infra-Red Gas Analyser (IRGASON system; see Sect. 2.3.7) with an exchange coefficient defined by the DBLS fluxes to finally calculate flux estimates of $\mathrm{H}_{2} \mathrm{O}$ and $\mathrm{CO}_{2}$. In other words, with $u_{*}$ and $L$ solved with the DBLS, Eq. (1) can be evaluated using structure parameters of trace gases $x$, where in this case $x$ represents the specific density, $q_{x}$, of $\mathrm{H}_{2} \mathrm{O}$ or $\mathrm{CO}_{2}$.

\subsubsection{Eddy covariance and ancillary micrometeorological measurements}

A continuously running EC system was operated in the middle of the field (Fig. 1), comprising a three-dimensional sonic anemometer (Model CSAT-3, Campbell Scientific, Inc., Logan, Utah, USA) and an open-path infrared gas analyser (Model LI-7500, Li-Cor, Inc., Biosciences, Lincoln, Nebraska, USA). The sensors height was $2.34 \mathrm{~m}$ a.g.l. Raw data were sampled in $20 \mathrm{~Hz}$ mode and fluxes and averages were calculated as 30 min block averages using the TK3.11 software package developed at the University of Bayreuth, including corrections and quality control as given in Mauder and Foken (2011). Missing values in the calculated turbulent fluxes were filled with the marginal distribution sampling (MDS) method following Reichstein et al. (2005) which is implemented in the REddyProc software package (Wutzler et al., 2018). The station also included measurements of all components of the radiation budget (NR01, Hukseflux, Delft, the Netherlands), PAR (LI-190R, Li-Cor Inc. Biosciences, Lincoln, Nebraska, USA, and BF5, Delta-T Devices, Cambridge, UK), air temperature $\left(T_{\text {air }}\right)$, and humidity (HMP45C, Vaisala Inc., Helsinki, Finland) at $2.4 \mathrm{~m}$, and precipitation (Thies Clima type tipping bucket, distributed by Ecotech, Bonn, Germany) at $1.0 \mathrm{~m}$ a.g.l. Radiation measurements were taken at $2.5 \mathrm{~m}$. Soil heat flux, temperature, and moisture were measured next to the station, more specifically, this was performed using the following parameters: 3 times HFP01SC at 3 and $8 \mathrm{~cm}$, Hukseflux, the Netherlands; 3 times TCAV, Campbell Scientific, Logan, USA; and $1 \mathrm{~cm}$, $5 \mathrm{~cm}$, and 2 to $65 \mathrm{~cm}$ layer average, 2 times CS616, Campbell Scientific, Logan, USA, 2 to $6 \mathrm{~cm}$ layer average. In addition, we measured at five points distributed across the field using the wireless SoilNet sensor system (Bogena et al., 2010). One SoilNet point was placed next to the station, while the other four were placed next to the soil $\mathrm{CO}_{2}$ efflux chambers described above. Each SoilNet point comprised a single soil heat flux measurement at $5 \mathrm{~cm}$ (HFP01SC, see above) and combined temperature and soil water content measurements in depths of 1, 5, 10,20,50, and $100 \mathrm{~cm}$ (SMT100, Truebner $\mathrm{GmbH}$, Neustadt, Germany).

A second mobile EC station with instruments heights of $1.93 \mathrm{~m}$ a.g.l. was deployed in the immediate vicinity of 
the continuously monitoring station during the measurement campaign. The system comprised an IRGASON EC system (SN1185 Irgason EC150, Campbell Scientific, Inc., Logan, Utah, USA; PTB101B pressure sensor, Vaisala Inc., Helsinki, Finland) with an additional LI-7500 sensor (same manufacturer). Here, fluxes were processed with the LiCor EddyPro v6.2.2 software. Radiation (CM11 for global and CG2 for long-wave radiation, Kipp \& Zonen B.V., Delft, Netherlands), ground heat flux $(4 \times \mathrm{HFP} 01 \mathrm{SC}$ at $5 \mathrm{~cm}$ depth, Hukseflux, the Netherlands), and temperatures at depths of $2 \mathrm{~cm}(4 \times)$ and $8 \mathrm{~cm}(2 \times)$ were also measured at this station.

\subsubsection{Canopy-level measurements of reflectance and sun-induced fluorescence (SIF): FloxBox}

A field spectroscopy system was used (FLOX, JB Hyperspectral Devices UG, Düsseldorf, Germany) for canopy-level measurements of reflectance and SIF. FLOX is constructed for high temporal frequency acquisition of continuous topof-canopy optical properties with a focus on sun-induced chlorophyll fluorescence. The system is equipped with two spectrometers: an Ocean Optics FLAME S, covering the full range of Visible and Near-Infrared (VIS-NIR) and an Ocean Optics QEPro, with a high spectral resolution (Full Width at Half Maximum, FWHM, of $0.3 \mathrm{~nm}$ ) in the 650-800 nm range of the fluorescence emission. The optical input of each spectrometer is split between two fibre-optic cables that lead to a cosine receptor that measures solar irradiance and a bare fibre bundle that measures the target-reflected radiance. Spectrometers are housed in a Peltier thermally regulated box to keep the internal temperature lower than $25^{\circ} \mathrm{C}$ in order to reduce dark current drift. The signal is automatically optimized for each channel at the beginning of each measurement cycle, and two associated dark spectra are collected as well. Metadata such as spectrometer temperature, detector temperature and humidity, Global Positioning System (GPS) coordinates, and time are also simultaneously stored in the secure digital memory of the system. More detailed information about the system can be found in Wohlfahrt (2018) and in Campbell (2019).

\subsubsection{Regional level measurements of reflectance and sun-induced fluorescence (SIF): HyPlant}

An airborne high-performance imaging spectrometer (HyPlant) was used for regional-level measurements of the same quantities. Several flight lines over the $15 \mathrm{~km} \times 15 \mathrm{~km}$ study site with 1-3 m pixel resolution were used. HyPlant is a hyperspectral imaging system for airborne and ground-based use, developed as a cooperative effort between Forschungszentrum Jülich GmbH (Germany) and the company SPECIM (Oulu, Finland). It consists of two sensor heads, named DUAL and FLUO. The DUAL module is a line-imaging push broom hyperspectral sensor, which provides contiguous spectral information from 370 to $2500 \mathrm{~nm}$ in a single device that utilizes a standard objective lens with $3 \mathrm{~nm}$ spectral resolution in the VIS-NIR spectral range and $10 \mathrm{~nm}$ spectral resolution in the SWIR spectral range. The FLUO module measures the vegetation fluorescence signal with a separate push broom sensor that produces data at high spectral resolution $(0.25 \mathrm{~nm})$ in the spectral window between 670 and $780 \mathrm{~nm}$. The position and altitude sensor (GPS/INS sensor) provides, synchronously with the image data, aircraft position and altitude data for image rectification and geo-referencing. Both imagers are mounted in a single platform with the mechanical capability to align the field of view (FOV). A more detailed description of the sensor is given in Rascher et al. (2015).

Sun-induced fluorescence $\left(F_{687}\right.$ and $\left.F_{760}\right)$ was retrieved in the two oxygen absorption bands according to the improved Fraunhofer Line Discrimination (iFLD) method. The iFLD method was initially proposed by Alonso et al. (2008) and was adapted to allow SIF retrievals from the FLUO module of the HyPlant sensor (Rascher et al., 2015). Surface reflectance and vegetation indices were calculated after an atmospheric correction using the MODTRAN software package was applied. The atmospheric correction was performed using the MODTRAN software package (for an overview of the data processing of HyPlant, see Siegmann et al., 2019). For the reason of easier comparison of SIF values with other methods of this paper, the commonly used SIF units $\left(\mathrm{mW} \mathrm{m}^{-2} \mathrm{sr}^{-1} \mathrm{~nm}^{-1}\right)$ were replaced by a substitute (nmol m${ }^{-2} \mathrm{sr}^{-1} \mathrm{~s}^{-1}$ ) using conversion factors of 6.35 for and 5.74 for $F_{687}$ and $F_{760}$, respectively.

\subsubsection{Boundary layer and cloud remote sensing measurements}

The JOYCE remote sensing facility (Löhnert et al., 2015) (located at a distance of $5 \mathrm{~km}$ from the test site) provided continuous information about boundary layer and cloud characteristics. Specifically, microwave and lidar measurements were used to compare the CLASS model results (see Sect. 2.4) with the inferred boundary layer depth. This comparison was completed by vertical profiles measured by the routine radio soundings at Essen (station ID EDZE/10410 at a distance of $75 \mathrm{~km})$.

\subsection{Modelling from leaf to landscape scales: CLASS}

The Chemistry Land-surface Atmosphere Soil Slab (CLASS, https://classmodel.github.io/, last access: 21 August 2020) is a model that couples the soil-vegetation-atmospheric processes and is used to interpret the observations and analyse the interaction of scales (Vilà-Guerau de Arellano, et al., 2015). It contains a leaf-level representation of photosynthesis and stomatal aperture (leaf resistance). By upscaling this leaf resistance to the canopy level (surface canopy resistance), it connects with the soil processes and boundary layer diurnal dynamics. In Sect. 2.4.1 and 2.4.2, we will 
subsequently discuss the two main modules of CLASS that we will target in this paper, i.e. the leaf level photosynthesis module and the mixed-layer module.

\subsubsection{Modelling leaf-level photosynthesis}

Leaf-level photosynthesis was modelled using the representation of photosynthetic biochemistry, as included in CLASS (Vilà-Guerau de Arellano et al., 2015), which was originally developed by Goudriaan (1986) and further adapted to meteorological applications by Jacobs and de Bruin (1997). As this model describes the relationship between stomatal conductance $\left(g_{\mathrm{s}}\right)$ and photosynthesis $(A)$, it is usually referred to as the $A-g_{\mathrm{s}}$ sub-model. In short, plant transpiration and $\mathrm{CO}_{2}$ assimilation as part of the surface energy balance model are represented by a two-big-leaves model, one for sunlit leaves and one for shaded leaves (Jacobs and de Bruin, 1997; Pedruzo-Bagazgoitia et al., 2017). The exchange at the leaf surface depends on the gradient of atmospheric $\mathrm{CO}_{2}$ and an internal leaf $\mathrm{CO}_{2}$ concentration, which depends on the water vapour deficit and leaf conductance. The $\mathrm{CO}_{2}$ exchange is upscaled to the canopy level by integrating over the leaf area index (LAI).

Available field measurements were used for improving the model settings at the leaf level. The parameters representing the initial value of the light use efficiency $\left(\alpha_{0}\right)$ and the temperature-normalized maximum leaf-level photosynthesis rate $\left(A_{\mathrm{m}, \max 298}\right)$ were fitted using light-response curves (Fig. 5) and $\mathrm{CO}_{2}$-response curves (Fig. 3b) collected on 8 May 2018 ( $1 \mathrm{~d}$ after IOP 1). Table 3 summarizes the optimized values used in the $A-g_{\mathrm{S}}$ (sub)model to simulate the leaf-level photosynthesis. The $A-\mathrm{PAR}$ curves contain only the lower light intensity values $\left(0-200 \mu \mathrm{mol} \mathrm{m}^{-2} \mathrm{~s}^{-1}\right)$ for which the light response is near linear and not limited by $\mathrm{CO}_{2}$ diffusion into the leaf. As leaf-level measurements of $A_{\max }$ indicated a decline in photosynthetic capacity in the course of the growing season (Fig. $5 \mathrm{c}$ ), we performed additional measurements of $A_{\mathrm{m}, \max 298}$ to represent the observed seasonal decline for IOP 2 and IOP 3 . The impacts on these optimized values are shown and discussed in the Supplement.

\subsubsection{Modelling the diurnal variability of landscape surface fluxes and boundary layer dynamics}

The fundamental assumption of the mixed-layer model is that under convective conditions the atmospheric boundary layer (ABL) dynamics lead to profiles of the meteorological state variables that are uniform (well-mixed) with height. As a result, these state variables are governed by horizontally averaged 0 -dimensional slab equations: one equation for the evolution through time of the slab variable and another for the difference between the residual layer (in the morning transition) and the free tropospheric values and the slab value, i.e. the jump at the interface between residual layer and $\mathrm{ABL}$. The ABL dynamics are governed by the mixed-layer equations of potential temperature (heat), specific humidity (moisture), $\mathrm{CO}_{2}$, and two horizontal wind momentum components. In addition, there is an equation that governs the boundary layer growth, which depends on the buoyancy flux at the surface and the jump in the virtual potential temperature at the interface between the atmospheric boundary layer and the free troposphere.

A key feature of the model is its representation of the subdaily variability of the land-atmosphere interactions (van Heerwaarden et al., 2010; Vilà-Guerau de Arellano et al., 2015). The net ecosystem exchange is calculated as a result of the assimilation of $\mathrm{CO}_{2}$ by plants and the $\mathrm{CO}_{2}$ soil efflux. We calculate the assimilation rate from photosynthesis and the stomatal aperture measurements at leaf level (see Sect. 2.4.1), upscaled to canopy level (Ronda et al., 2001). This model depends on the diurnal variability of PAR, temperature $\left(T_{\text {air }}\right.$ and $\left.T_{\text {air,p }}\right)$, and the water vapour deficit (VPD). The two-big-leaves approach is used (sunlit and shaded) to take the different contributions of direct and diffuse radiation into account (Pedruzo-Bagazgoitia et al., 2017). The soil efflux is calculated as a function of the soil temperature and moisture. Other relevant physical processes include a radiation transfer model, the Penman-Monteith equation included in the surface energy balance, and the possibility of adding large-scale forcings such as vertical subsidence motions and large-scale advection of momentum, heat, moisture, and $\mathrm{CO}_{2}$. Within the context of CloudRoots, it is important to mention that the model assumes a horizontal homogeneous surface. While the experimental field itself is quite homogeneous, it is surrounded by other land use types at a spatial scale that will affect the boundary layer. In that respect, and in setting the initial and boundary conditions for the numerical case, we assume that the boundary layer dynamic is governed by a sensible heat flux that is an aggregate of all the fields shown in Fig. $1 \mathrm{~b}$.

\section{Results: integrating spatio-temporal scales from leaf to boundary layer}

This section is structured following the five facets of the diurnal interactions between the land and the atmosphere outlined in the introduction.

\subsection{Leaf-level exchange of $\mathrm{H}_{2} \mathrm{O}$ and $\mathrm{CO}_{2}$ : observations and modelling}

We combine leaf-level and sap flow measurements of tiller assimilation and transpiration with leaf-level assimilation modelled by CLASS, $A-g_{\mathrm{s}}$ representation, to study their variation during the growing season and the impact of unsteady PAR due to the presence of clouds. 
Table 3. Parameters representing the maximum leaf-level photosynthesis rate $\left(A_{\mathrm{m}, \max 298}\right)$ and the initial value of light-use efficiency $\left(\alpha_{0}\right)$ under low light, as adjusted in the original $A-g_{\mathrm{s}}$ model to represent plant-specific photosynthesis characteristics for winter wheat (ww). $A_{\mathrm{m}, \max 298}$ was initially fitted using the $A-\mathrm{Ci}$ curves and $\alpha_{0}$ is fitted using the $A$-PAR curves taken during IOP 1 (Fig. 5). For IOP 2 and IOP $3, A_{\mathrm{m}, \max 298}$ values were fitted only on leaf-level measurements of $A_{\max }$. The values of IOP 1 were used as numerical settings for the CLASS model runs (Fig. 16). The equivalence to typical values of the commonly used in the Farquhar-Berry-von Caemmerer (FBvC) model of leaf photosynthesis (Farquhar et al., 1980) is given in Table S1 at the Supplement.

\begin{tabular}{lrrrr}
\hline Fitted model variable & $\begin{array}{r}\text { Default value } \\
\text { (for C3 plants) }\end{array}$ & $\begin{array}{r}\text { Fitted } \\
\text { ww } \\
\text { IOP 1 }\end{array}$ & $\begin{array}{r}\text { Fitted } \\
\text { ww } \\
\text { IOP 2 }\end{array}$ & $\begin{array}{r}\text { Fitted } \\
\text { Ww } \\
\text { IOP 3 }\end{array}$ \\
\hline Mesophyll conductance at $298 \mathrm{~K}_{\left(\mathrm{mm} \mathrm{s}^{-1}\right)}$ & 7.0 & 10.0 & 10.0 & 10.0 \\
Maximum leaf-level photosynthesis rate $\left(A_{\mathrm{m}, \max 298)}\left(\mathrm{mg} \mathrm{m}^{-2} \mathrm{~s}^{-1}\right)\right.$ & 2.2 & 1.926 & 1.0 & 0.2 \\
\hline light-use efficiency $\left(\alpha_{0}\right)\left(\mathrm{mg} \mathrm{J}^{-1}\right)$ & 0.017 & 0.0053 & 0.0053 & 0.0053 \\
\hline
\end{tabular}

\subsubsection{Stomatal conductance and sap flow}

Our leaf-level measurements revealed clear diurnal patterns in $g_{\mathrm{sw}}$ during all the IOPs (Fig. 3). The observed daily maximum $g_{\mathrm{sw}}$ decreased over the growing season. This daily maximum $g_{\mathrm{sw}}$ occurred at an earlier time during each IOP. Specifically, the $30 \mathrm{~min}$ average daily maximum $g_{\mathrm{sw}}$ declined from $0.84 \mathrm{~mol} \mathrm{~m}^{-2} \mathrm{~s}^{-1}$ (around 10:00 UTC, 12:00 LT) during IOP 1 and $0.83 \mathrm{~mol} \mathrm{~m}^{-2} \mathrm{~s}^{-1}$ (around 10:00 UTC) during IOP 2 to $0.30 \mathrm{~mol} \mathrm{~m}^{-2} \mathrm{~s}^{-1}$ (between 05:30 and 06:30 UTC) during IOP 3 . The weather during IOP 2 was characterized by large cumulus clouds passing over the field site, which were made visible in the large fluctuations in PAR (Figs. 3b, 11 and 12). The cloud-related changes in light intensity induced consistent stomatal opening-closing responses during IOP 2 . The relatively low $g_{\text {sw }}$ observed during IOP 3 probably reflects the continuing drought that characterized the 2018 growing season in combination with the relatively high VPD and high temperatures. Sap flow measurements were performed during IOP 2 and IOP 3 (Fig. $3 b$ and c) and one earlier non-IOP day (7 June) (Fig. 4). Measurements of sap flow revealed clear diurnal patterns for all measurement days and consistent responses to cloud-induced changes in light intensity during IOP 2 (Fig. 3b). These responses were comparable to the observed responses in $g_{\text {sw }}$ during IOP 2. Interestingly, the notable decline in leaf-level $g_{\text {sw }}$ between IOP 2 and IOP 3 was neither reflected in the measurements of sap flow nor in the ET measurements with the eddy covariance. For IOP 3, the ET measured by the eddy covariance had still maximum values of $300 \mathrm{~W} \mathrm{~m}^{-2}$. Thereafter, the decrease in ET started 1 week afterwards (5 July) with values lower than $100 \mathrm{~W} \mathrm{~m}^{-2}$. This discrepancy could partly be explained by increases in VPD and wind speed between IOP 2 and IOP 3. The more probable causes are senescence effects on physiological control of transpiration and the physical reactions to heat of the wheat tillers, which were noticeably wilting between IOP 2 and IOP 3 . This observation has so far not been reported in the literature. Further studies of the relationships between senescence and simultaneously occurring changes in the heat and physical properties of wheat tillers are needed to explain this phenomenon.

\subsubsection{Observed versus modelled leaf-level photosynthesis}

One of the main aims in CloudRoots is to improve the mechanistic modelling of photosynthesis and stomatal aperture. To this end, we calibrate the constants of the $A-g_{\mathrm{s}}$ model using systematic in situ field observations. Figure 5 shows the dependencies of leaf-level photosynthesis of $A_{\text {leaf }}$ on PAR (Fig. 5a) and the leaf-internal $\mathrm{CO}_{2}$ concentration (Fig. 5b) and the long-term decline in maximum light-saturated photosynthesis (Fig. 5c). Our observations indicate the need to calibrate the model depending on the functional type of the plant, in particular the dependence of $A_{\text {leaf }}$ on PAR, during the field campaign. Table 2 summarizes the new constant values used in the $A-g_{\mathrm{s}}$ model adjusted to the winter wheat crop conditions.

Figure 6 shows a comparison of the model results of $A_{\text {leaf }}$ using the new constants and the measurements of $A_{\text {leaf }}$ and NPP together with the diurnal variation in PAR and VPD during the three IOPs. Our measurements and model results of $A_{\text {leaf }}$ showed clear diurnal patterns during each IOP, and a consistent decline over the three IOPs. The decline in $A_{\text {leaf }}$ was comparable to the decline in $A_{\max }$ (Fig. 5c) and probably reflects a combination of seasonal decay in photosynthetic capacity and increasing stomatal limitations owing to persistent drought, especially during IOP 3 . The magnitude of the seasonal decline in $A_{\text {leaf }}$ was comparable to the seasonal decline in NPP derived from EC data. Cloud-induced changes in PAR during IOP 2 also induced changes in $A_{\text {leaf }}$. The $A-g_{\mathrm{S}}$ model reproduced the diurnal patterns in $A_{\text {leaf }}$ during each IOP, as well as the cloud-induced changes in $A_{\text {leaf }}$ during IOP 2 . The agreement is very satisfactory during IOP 1 , which was characterized by cloudless conditions and the maturity of winter wheat. The model underestimated $A_{\text {leaf }}$ during IOP 3 , which was a result of the strong stomatal limitations that influenced the measurement of $A_{\max }$ on which the 

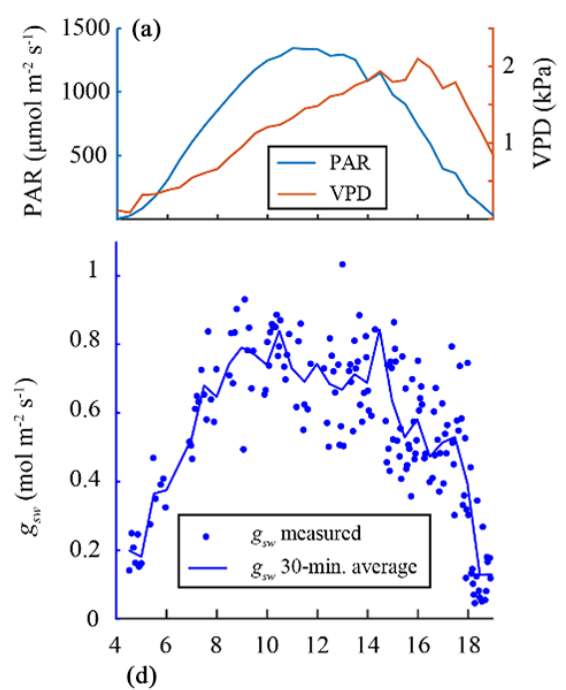

Time (UTC)
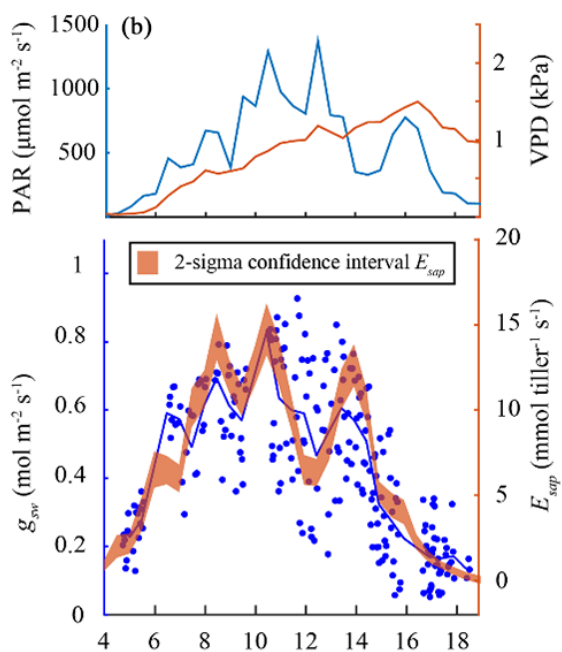

(e)
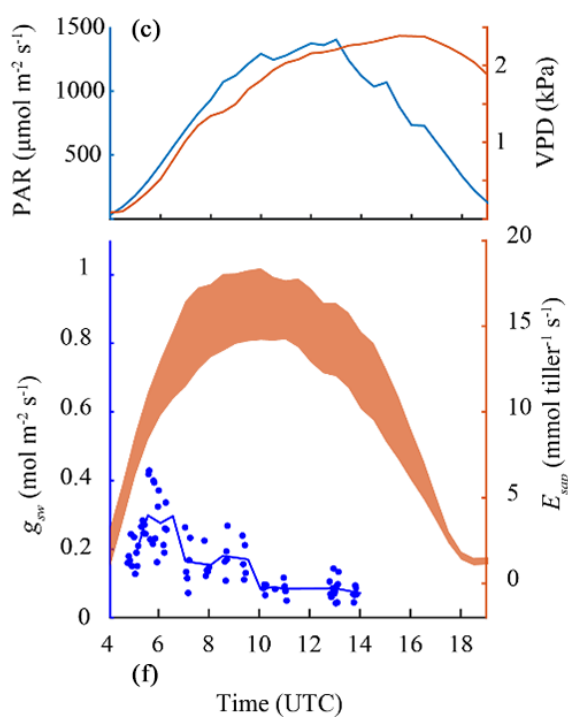

Figure 3. Diurnal changes in photosynthetically active radiation (PAR) and vapour pressure deficit (VPD) measured for (a) IOP 1, (b) IOP 2, and (c) IOP 3. Leaf-level measurements of stomatal conductance of water vapour $\left(g_{\text {sw }}\right)$ in (b) and (c) compared to tiller-level measurements of sap flow $\left(E_{\mathrm{sap}}\right)$. Leaf-level measurements of $g_{\mathrm{sw}}$ (blue markers) were averaged over 30 min intervals (blue line). Sap flow measurements represent the $1 \mathrm{SD}$ confidence interval (shaded region) of measurements on 24 tillers averaged over 30 min timescales.

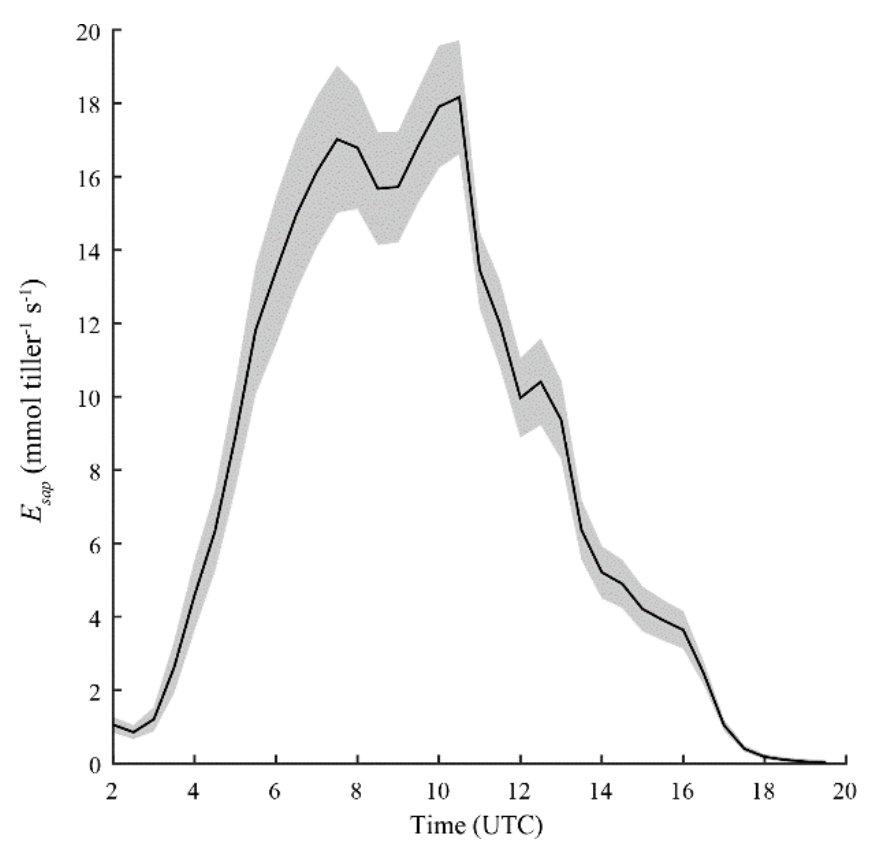

Figure 4. Sap flow measured using the heat balance method for 7 June 2018 (non-IOP day).

model parameterization from IOP 3 was based. The model furthermore overestimates the decline in $A_{\text {leaf }}$ between 14:00 and 19:00 UTC, which probably reflects a misrepresentation of the temperature and VPD sensitivity of Triticum aestivum.

\subsection{Canopy-level partitioning of the net $\mathrm{H}_{2} \mathrm{O}$ and $\mathrm{CO}_{2}$ fluxes between soil and plant processes}

Moving from leaf to canopy scale, we analyse the detailed profiles of micrometeorology and carbon dioxide collected using the elevator and infer vertical assimilation profiles and the diurnal variability in the surface contributions to ET and NEE.

\subsubsection{Concentration profiles of $\mathrm{H}_{2} \mathrm{O}$ and $\mathrm{CO}_{2}$, temperature and wind speed}

Figure 7 shows selected 30 min mean profiles of $\chi \mathrm{H}_{2} \mathrm{O}$ and $\chi \mathrm{CO}_{2}$, temperature, and wind speed versus height $(z)$ above ground level during IOP 1 and IOP 2. Over the diurnal cycle, $\chi \mathrm{CO}_{2}$ concentrations fell between 08:00 and 13:00 UTC from 370 to $360 \mu \mathrm{mol} \mathrm{mol}^{-1}$ in the mid-canopy during IOP 1 but stagnated slightly below $370 \mu \mathrm{mol} \mathrm{mol}{ }^{-1}$ during IOP 2 . This seasonal reduction in $\mathrm{CO}_{2}$ uptake was also observed in measured $A_{\text {leaf }}$, i.e. see the decrease of the maximum values in Fig. 6. The lowest values were observed during local noon, simultaneous with the highest PAR values (Fig. 5b). $\chi \mathrm{CO}_{2}$ minima were located in the upper third of the canopy during IOP 1 and during the middle third during IOP 2 . The highest $\chi \mathrm{CO}_{2}$ values were found near the soil surface due to soil respiration, lower light intensity caused by shadowing, and a low amount of photosynthetic organs in the stems. Maximum $\chi \mathrm{CO}_{2}$ concentrations were measured in the morning and evening hours and peaked at about 475 and $420 \mu \mathrm{mol} \mathrm{mol}^{-1}$ during IOP 1 and IOP 2, respectively. The photosynthetic $\mathrm{CO}_{2}$ uptake by plants is highly related to plant transpiration. Consequently, $\chi \mathrm{H}_{2} \mathrm{O}$ in the canopy space was higher than in 

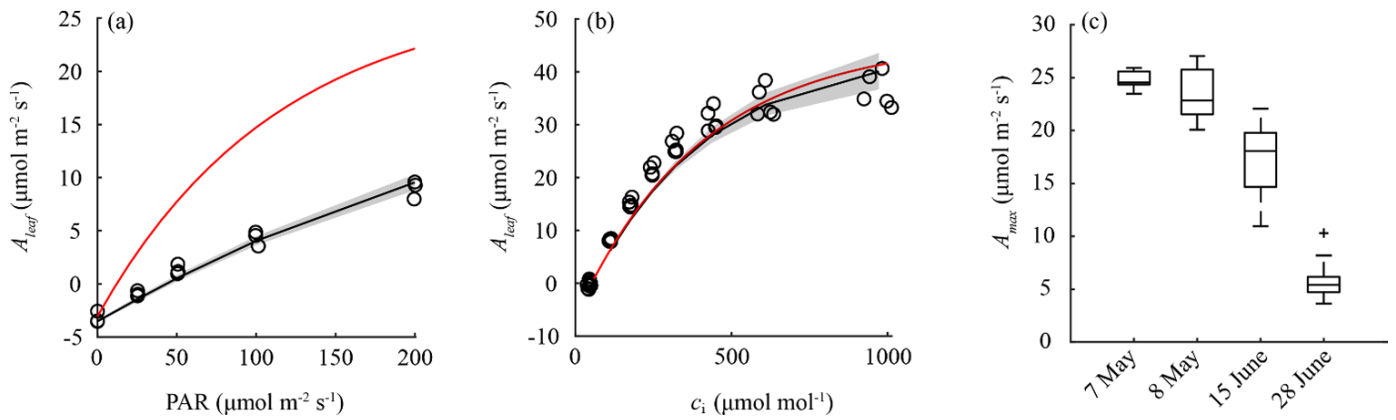

Figure 5. Measurements of leaf-level photosynthesis ( $\left.A_{\text {leaf }}\right)$ as a function of photosynthetically active radiation (PAR) (a) and leaf interior $\mathrm{CO}_{2}$ concentrations $\left(c_{\mathrm{i}}\right)$ (b). These results were used to parameterize the $A$ - $g_{\mathrm{s}}$ model for IOP1, as indicated by the black line and shaded 1 SD confidence interval. The red line indicates the model response using the default parameter values. (c) Observed and modelled seasonal decline in maximum light-saturated photosynthesis $\left(A_{\max }\right)$. Boxes indicate the variability in observed values in $A_{\text {max }}$; red markers indicate the modelled net photosynthesis rate using fitted values for $A_{\mathrm{m}, \max 298}$. Fitted and default $A-g_{\mathrm{s}}$ model parameter values are indicated in Table 3 .
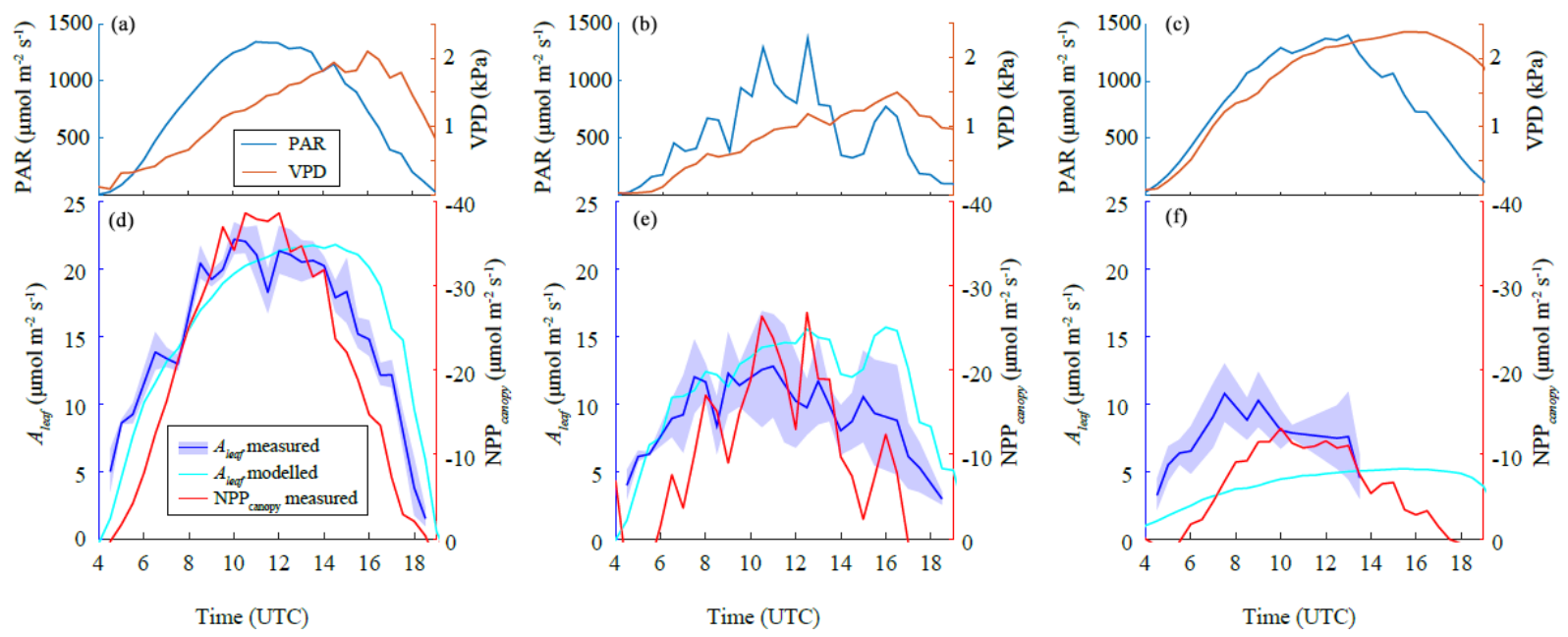

Figure 6. Measured leaf-level photosynthesis $\left(A_{\text {leaf }}\right.$ ) compared to modelled $A_{\text {leaf }}$ using the $A-g_{\mathrm{s}}$ model and canopy-level net primary productivity (NPP canopy) for (a) IOP 1, (b) IOP 2, and (c) IOP 3. Measurements of $A_{\text {leaf }}$ were plotted as 30 min averages (blue line) and their 1 SD confidence interval (shaded region). Panels (d), (e), and (f) show diurnal changes in photosynthetically active radiation (PAR) and vapour pressure deficit (VPD) measured for each IOP.

the air above the canopy. The highest values were found directly above the soil surface and were caused by evaporation and due to plant transpiration within the canopy.

The highest temperatures appeared near the canopy top (Fig. 7d, e, j and 1). In the late morning of IOP 2, the temperature reached a distinct maximum just below the canopy top (Fig. 7j). This phenomenon has been reported in previous studies (Ney and Graf, 2018) and is caused by the changing solar incidence angle. A low angle of incidence in the morning and afternoon limited the heating to an area just below the canopy surface. Previous studies have shown that the presence of such a pronounced temperature maximum has the potential to increase thermal stability within the canopy and thus inhibit the vertical turbulent exchange of sensible heat (Gryning et al., 2001; Ney and Graf, 2018; Sikma et al., 2020). It can be assumed that the sensible heat flux within the dense plant stand was largely determined by the entire canopy. In other words, during the day, mixing near the soil surface was impeded by stable temperature stratification, while in the evening cooling expanded upwards from the soil surface (Fig. 7f). In general, the processes described above were more pronounced during IOP 2 with its greater canopy height than with the lower canopy during IOP 1 . The vertical wind profile showed consistently low wind speeds within the dense canopy $\left(<0.5 \mathrm{~m} \mathrm{~s}^{-1}\right)$. Above the canopy layer, the wind speed increased in a log-like profile up to a maximum of $2 \mathrm{~m} \mathrm{~s}^{-1}$.

\subsubsection{Profiles of gross primary production}

The detailed profile observations presented in the previous section enable us to calculate height-resolved estimates of 


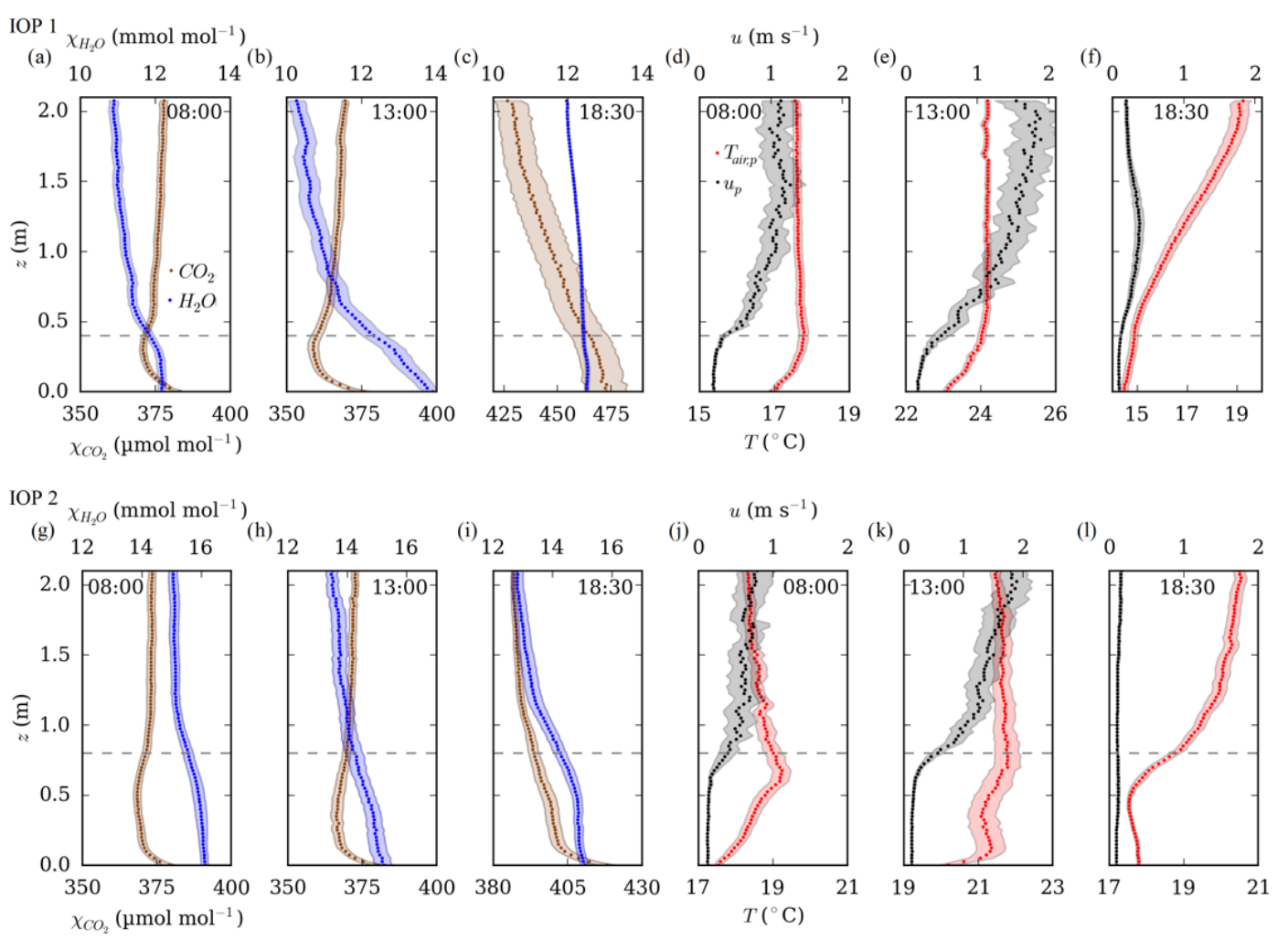

Figure 7. Selected $\left(08: 00,13: 00\right.$ and 18:30 UTC) 30 min mean profiles of the $\mathrm{H}_{2} \mathrm{O}$ and $\mathrm{CO}_{2}$ mole fractions $\left(\chi \mathrm{H}_{2} \mathrm{O}, \chi \mathrm{CO}_{2}\right)$, wind speed $\left(u_{\mathrm{p}}\right)$, and temperature $\left(T_{\text {air, }}\right)$ measured at high vertical resolution during IOP 1 (upper row) and IOP 2 (lower row). Shaded areas indicate the $95 \%$ confidence interval resulting from the standard deviation between individual profiles sampled within a 30 min average interval. The dashed lines indicate the canopy heights.

gross primary production $A$. Using the $30 \mathrm{~min}$ averages of the vertical profiles for temperature, moisture, and $\mathrm{CO}_{2}$ in the canopy, $A$ is determined using the $A-g_{\mathrm{s}}$ model (Jacobs et al., 1997; Ronda et al., 2001). $A\left(\mathrm{mg} \mathrm{m}^{-2} \mathrm{~s}^{-1}\right)$ is calculated as follows:

$A=\operatorname{LAD}\left(A_{\mathrm{m}}(h)+R_{\mathrm{d}}(h)\right)\left[1-\exp \left(\frac{-\alpha \operatorname{PAR}(h)}{A_{\mathrm{m}}(h)+R_{\mathrm{d}}(h)}\right)\right]$,

where LAD $\left(\mathrm{m}_{\text {leaf }}^{2} \mathrm{~m}^{-3}\right)$ is the leaf area density, $A_{\mathrm{m}}(h)$ is the $\mathrm{CO}_{2}$ primary productivity $\left(\mathrm{mg} \mathrm{m}_{\text {leaf }}^{2} \mathrm{~s}^{-1}\right)$ as a function of height $h, R_{\mathrm{d}}(h)\left(\mathrm{mg} \mathrm{m}_{\text {leaf }}^{2} \mathrm{~s}^{-1}\right)$ is the $\mathrm{CO}_{2}$ dark respiration as a function of $h, \alpha\left(\mathrm{mg} \mathrm{J}^{-1}\right)$ is the light use efficiency, and $\operatorname{PAR}(h)\left(\mathrm{W} \mathrm{m}_{\text {leaf }}^{-2}\right)$ is the amount of available photosynthetically active radiation within the canopy. Solar-zenith-anglerelated variation in PAR intrusion and differences between atmospheric and skin values for temperature, moisture, and $\mathrm{CO}_{2}$ are neglected. Figure 8a shows the winter wheat LAD applied in the calculation.

Figure $8 \mathrm{~b}$ shows that the entire canopy contributes to the photosynthetic activity but with maximum $A$ at $h / h_{\mathrm{c}}=0.7$ ( $h_{\mathrm{c}}$ : canopy height). This is primarily caused by the extinction of PAR within the canopy and reduced leaf density distribution close to the ground (Fig. 8a). Maximum diurnal productivity is found at around $h / h_{\mathrm{c}}=0.7$, with the diurnal maximum at 12:00 UTC. Integration over the canopy shows minor discrepancies with respect to the bulk $A-g_{\mathrm{s}}$ model calculation, as the profile data allows for a more precise evaluation of photosynthetic activity. The profile measurements combined with Eq. (2) therefore allows for an improved modelling of the photosynthetic $\mathrm{CO}_{2}$ uptake of vegetation depending on height and the understanding of mechanisms. More accurate estimates of $\mathrm{CO}_{2}$ gross primary production still require improved knowledge of plant canopy micrometeorology (Drewry et al., 2014).

\subsubsection{Profile-based partitioning of $\mathrm{H}_{2} \mathrm{O}$ and $\mathrm{CO}_{2}$}

Figure 9 shows the measured fluxes of latent heat, NEE, and soil respiration, as well as their partitioning based on the inversion of vertical high-resolution concentration profiles into the soil evaporation and plant transpiration and the $R_{\mathrm{S}}$ and NPP components. In this section, positive values indicate a flux from the surface and plants into the atmosphere and vice versa. During IOP 1 , measured latent heat flux $\left(L_{\mathrm{v}} E\right.$, hereafter referred to as $\mathrm{ET}_{\mathrm{ec}}$ ) showed a typical daily pattern under clear sky conditions (Fig. 9a) with maximum $\mathrm{ET}_{\mathrm{ec}}$ at noon $\left(345 \mathrm{~W} \mathrm{~m}^{-2}\right)$. Evaporation $E$ of both methods dis- 
(a)

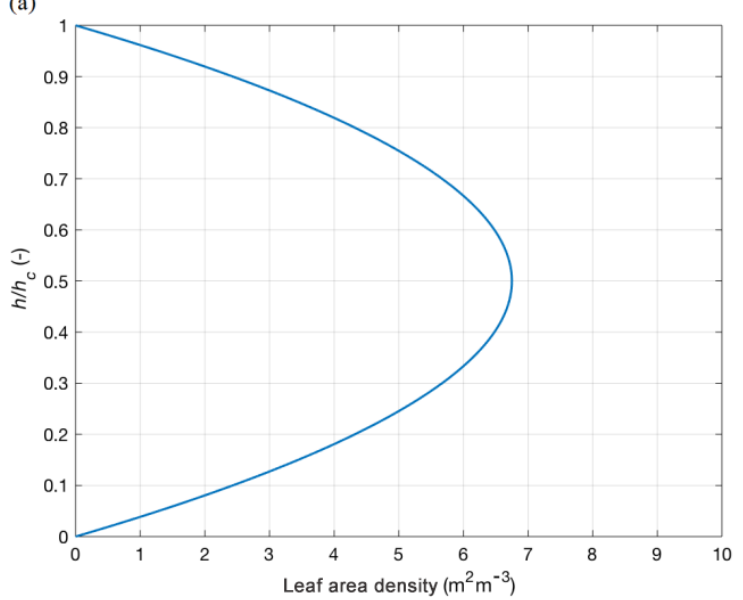

(b)

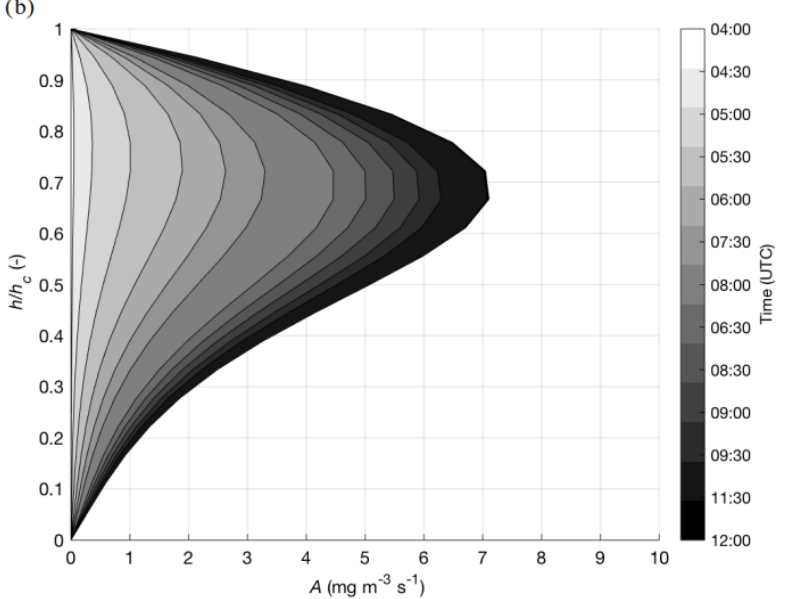

Figure 8. (a) Leaf area density $\left(\mathrm{m}_{\text {leaf }}^{2} \mathrm{~m}^{-3}\right)$ on 7 May 2018 as a function of height $(h)$ normalized to the maximum canopy $h\left(h_{\mathrm{c}}\right)$. The profile is typical for winter wheat, as defined by Olesen et al. (2004). (b) Time evolution of $\mathrm{CO}_{2}$ gross primary production $A$ (mg $\mathrm{m}^{-3} \mathrm{~s}^{-1}$ ) on 7 May 2018 as function of $h$ normalized to $h_{\mathrm{c}}$. The profile is obtained using the profile measurements and using Eq. (2).
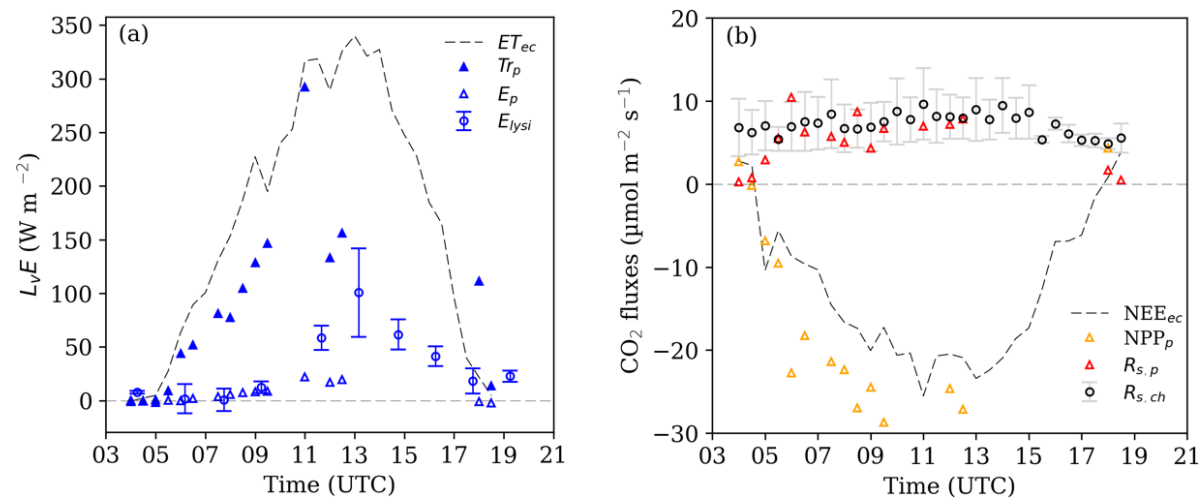

Figure 9. Source partitioning results for (a) $\mathrm{H}_{2} \mathrm{O}$ and (b) $\mathrm{CO}_{2}$ fluxes for IOP 1. Dashed grey lines show the measured latent heat flux (ET $\mathrm{ec}$ ) and net ecosystem exchange $\left(\mathrm{NEE}_{\mathrm{ec}}\right)$ in half-hourly time steps. Values with subscript index $p$ indicate estimates based on inversed profile concentration measurements (Sect. 3.4). Error bars for evaporation calculated from microlysimeters $\left(E_{\text {lysi }}\right)$ and soil respiration measurements $\left(R_{\mathrm{S}, \mathrm{ch}}\right)$ indicated to $1 \mathrm{SD}$. (ET $\mathrm{ET}_{\mathrm{ec}}$ : evapotranspiration measured as latent heat flux $L_{\mathrm{V}} E$ by the eddy covariance system; $E$ : evaporation; $\operatorname{Tr}_{p}$ : transpiration; NPP: above-ground net primary production; $R_{\mathrm{S}}$ : soil respiration).

played comparable values in the morning and evening but differed at midday. In the morning, the evaporation estimated using the profile measurements and method $\left(E_{\mathrm{p}}\right)$ and the lysimeter observations $\left(E_{\text {lysi }}\right)$ both consistently suggested low $E$ / ET fractions with $E$ below $10 \mathrm{~W} \mathrm{~m}^{-2}$. Towards noon, $E_{\mathrm{p}}$ increased to 25 and $E_{\text {lysi }}$ to $60 \mathrm{~W} \mathrm{~m}^{-2}$, and in the afternoon $E_{\text {lysi }}$ reached a maximum of $101 \pm 41 \mathrm{~W} \mathrm{~m}^{-2}$ (no $E_{\mathrm{p}}$ available). Estimated $T r_{p}$ increased to about $290 \mathrm{Wm}^{-2}$ at 11:00 UTC, this being the highest diurnal proportion of ET. Lower $\operatorname{Tr}_{p}$ levels around 12:00 UTC are probably due to a sub-optimal performance of the profile-based partitioning at this particular time. For example, none of the available inversion methods, including the algorithm by Santos et al. (2011) used here, include the effect of local thermal stability varying with height. Figure 7 demonstrates that thermal stability increased from the canopy top towards the ground around noon of IOP 1 (Fig. 7e), which may have contributed to the large increase of humidity towards the surface (Fig. 7b) due to the lack of mixing.

Variations in $\mathrm{CO}_{2}$ fluxes NEE, NPP, and $R_{\mathrm{S}}$ during IOP 1 are shown in Fig. 9b. $\mathrm{NEE}_{\mathrm{ec}}$ followed a typical diurnal cycle, with strong negative fluxes during the day and slightly positive values (carbon source) during transition times. The highest NEE was observed before noon $\left(-25 \mu \mathrm{mol} \mathrm{m}^{-2} \mathrm{~s}^{-1}\right)$. $\mathrm{NPP}_{\mathrm{p}}$ followed the graph of $\mathrm{NEE}_{\mathrm{ec}}$, with higher values $\left(-26 \mu \mathrm{mol} \mathrm{m}^{-2} \mathrm{~s}^{-1}\right)$ in the morning hours than during the afternoon under comparable PAR values. This behaviour coincides with the photosynthesis rate observed at leaf level in Fig. 6a and provides further evidence that carbon uptake by plants was limited due to stomatal occlusion caused by the increase in VPD (Fig. 6a) and/or $T_{\text {air }}$ in the afternoon. Profile-based $R_{\mathrm{S}, \mathrm{p}}$ ranged between 0.5 and $6 \mu \mathrm{mol} \mathrm{m} \mathrm{m}^{-2} \mathrm{~s}^{-1}$ 

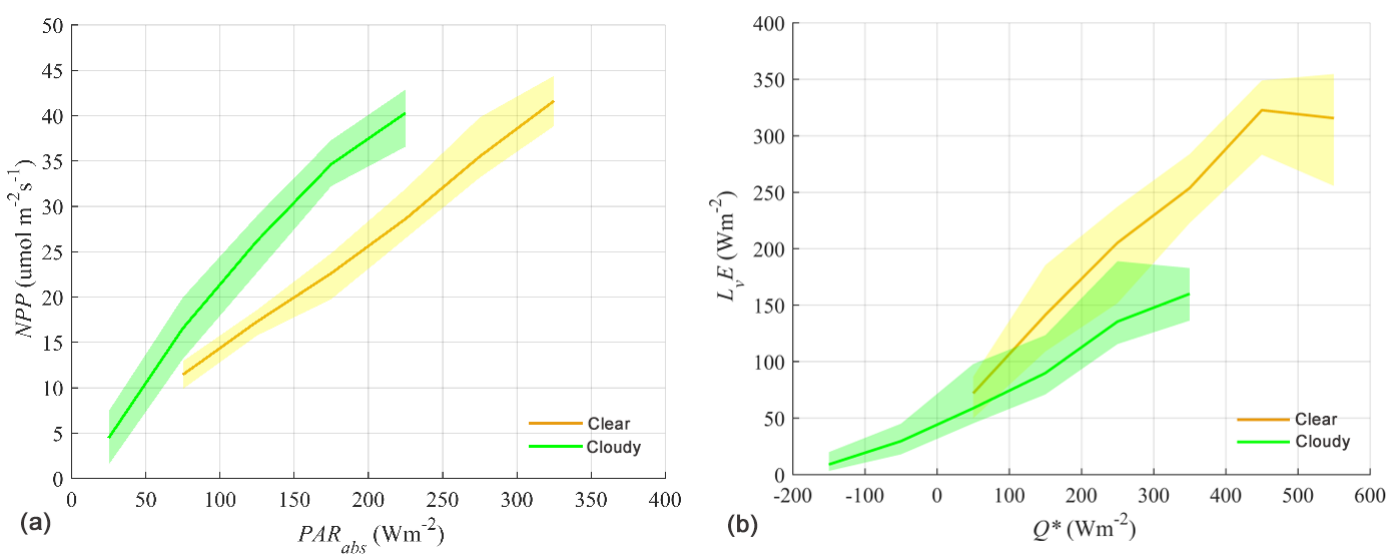

Figure 10. (a) Net primary production (NPP) versus photosynthetic active radiation (PAR). (b) Latent heat $\left(L_{\mathrm{v}} E\right)$ versus net radiation $\left(Q^{*}\right)$. In both figures, the observation period encompasses clear and cloudy skies during a 2-week period starting on 7 May 2018 at 03:30 UTC (sunrise) and ending on the 20 May 2018 at 19:40 UTC (sunset). The solid line represents the median of the data. The lower and upper boundaries of the shaded area are the 25 th and 75 th percentiles of the data, respectively.

with higher values around noon. Compared to measured $R_{\mathrm{S}, \mathrm{ch}}, R_{\mathrm{S}, \mathrm{p}}$ lay within the standard deviations of $R_{\mathrm{S}, \mathrm{ch}}$, though $R_{\mathrm{S}, \mathrm{p}}$ was significantly lower during the morning and evening hours.

\subsection{Effects of clouds on surface turbulent fluxes}

\subsubsection{Cloud-induced diffuse fertilization effect on evapotranspiration}

One of the main aims of CloudRoots was to obtain observational evidence of the effects of clouds on the $\mathrm{CO}_{2}$ assimilation and ET. Figure 10 shows the net primary production (NPP) (Fig. 10a) and $L_{\mathrm{v}} E$ (Fig. 10b), both measured using the eddy covariance, observed under a wide range of clear and cloudy skies as a function of PAR and compared to $Q^{*}$ at the top of the canopy (van Diepen and Moene, 2019). We analyse a 2-week period of observations, between 7 and 20 May 2018. The effect of the different direct and diffuse radiation due to cloud perturbations is distinguishable with an enhancement of NPP under clear conditions whereas $L_{\mathrm{V}} E$ is reduced. Clouds affect plant photosynthesis by increasing the fraction of diffuse solar radiation that arrives at the top of the canopy (Kanniah et al., 2012). With a larger contribution of diffuse solar radiation and within the canopy, the radiation spreads more equally over all leaves and thereby increases the light-use efficiency of a canopy (Farquhar and Roderick, 2003). At a constant level of radiation at the top of the canopy, the increased light-use efficiency results in enhanced canopy photosynthesis, which is known as the diffuse fertilization effect (Roderick et al., 2001). This phenomenon is especially noticeable for canopies with a high LAI (Knohl and Baldocchi, 2008; Dengel and Grace, 2010). In CloudRoots and due to the high values of LAI (values between 4.5 and $5.5 \mathrm{~m}^{-2}$ ), we expect situations in which diffuse fertilization occurs, but here the question is how it influences
$L_{\mathrm{v}} E$. Previous large-eddy simulation modelling studies by Pedruzo-Bagazgoitia et al. (2017) have shown that under conditions dominated by clouds with a small optical depth, i.e. thin clouds, $L_{\mathrm{v}} E$ is enhanced with respect to its clear-sky values at the same radiation level.

We find that the observed $L_{\mathrm{v}} E$ is higher rather than lower during clear conditions (less diffuse light) than under more diffused cloudy conditions. At constant $Q^{*}$, the median of $L_{\mathrm{v}} E$ is always higher under clear skies than for cloudy skies. The diffuse fraction plays a minor role and the decrease on $L_{\mathrm{v}} E$ under cloudy conditions is mainly due to the reduction in the incoming shortwave radiation. Our observations indicate that $L_{\mathrm{v}} E$ is driven by the partitioning of direct and diffuse radiation but also other effects such as diurnal variations of temperature, and the link to VPD may partially compensate for the different distribution of direct and diffuse radiation caused by clouds. The higher VPD values during the day partly offset the more optimal PAR conditions and therefore cause a closing of the stomatal that leads to decreases in $L_{\mathrm{V}} E$. For both clear and cloudy skies, the shaded area below the median represents conditions before 11:30 UTC and the shaded area above the median represents conditions after 11:30 UTC, i.e. implying a hysteresis loop (Zhang et al., 2014). This spread in $L_{\mathrm{V}} E$ at a constant level of $Q^{*}$ is caused by a difference in VPD between morning (before 11:30 UTC) and afternoon (after 11:30 UTC). This is because on a clear day the VPD raised rapidly due to its non-linear dependence on temperature relative to a cloudy day. In a typical clear day at CloudRoots, the value of $200 \mathrm{~W} \mathrm{~m}^{-2}$ for $Q^{*}$ is crossed twice: once in the morning and once in the afternoon. When $200 \mathrm{~W} \mathrm{~m}^{-2}$ is crossed in the morning, the VPD is around $1000 \mathrm{~Pa}$ and reaches a value of $2000 \mathrm{~Pa}$ in the afternoon. On the other hand, on a cloudy day with similar values of around $200 \mathrm{~W} \mathrm{~m}^{-2}$ the VPD remains almost constant through the entire day and with a value of $1000 \mathrm{~Pa}$ at 11:30 UTC. 

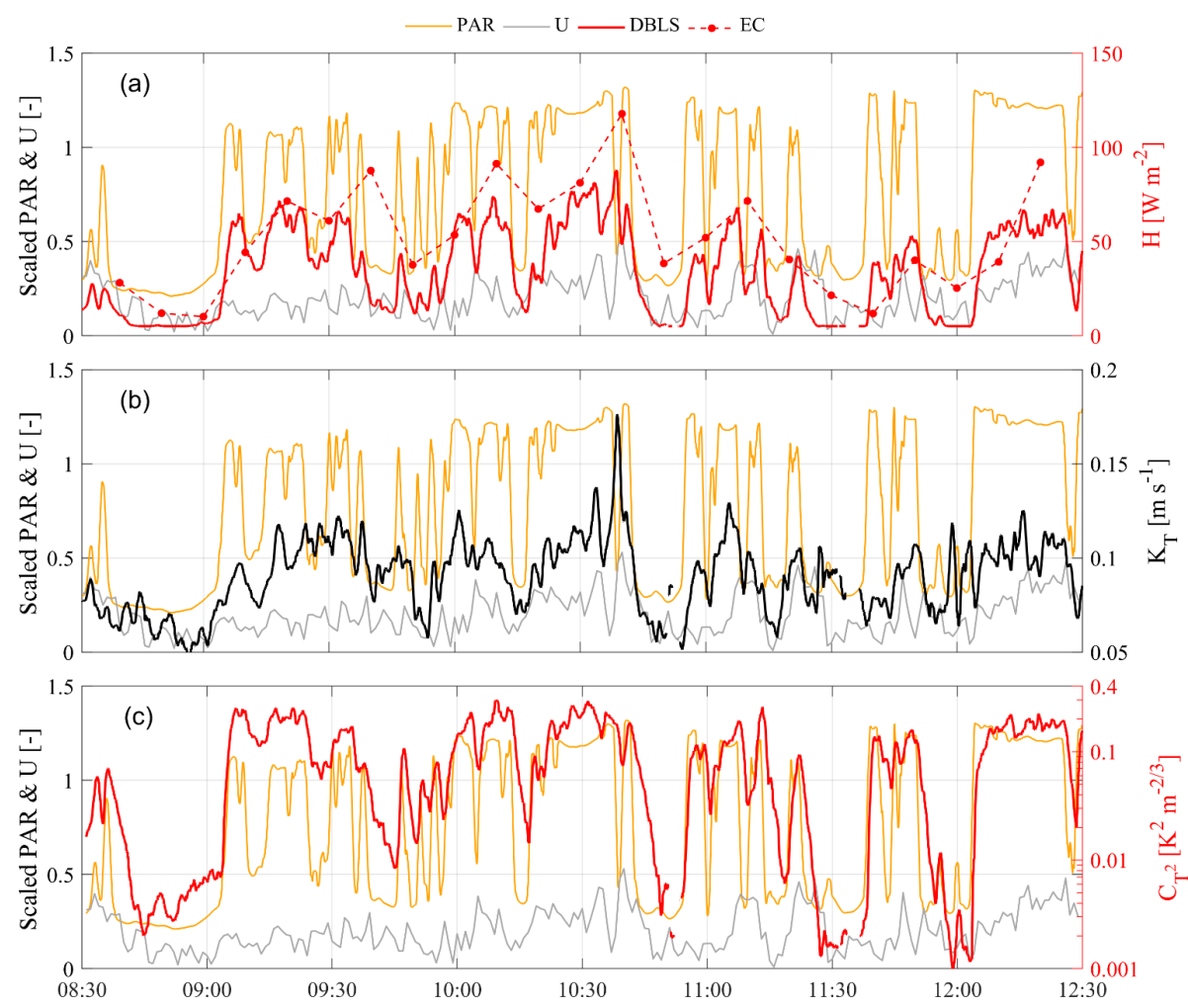

Figure 11. IOP 2 (15 June 2018) time series of (a) sensible heat flux $(H)$ at 1 min intervals with a displaced-beam laser scintillometer (DBLS) and at 10 min intervals with an eddy covariance system (EC), combined with scaled time series of photosynthetically active radiation (PAR, scaled by $\left.1500 \mu \mathrm{mol} \mathrm{m}^{-2} \mathrm{~s}^{-1}\right)$ and wind speed $\left(U\right.$, scaled by $\left.6 \mathrm{~ms}^{-1}\right)$; (b) turbulent exchange coefficient $K_{\mathrm{T}}$; and (c) structure parameter of temperature, $C_{T}^{2}$, that together make up $H$ in the DBLS method following Eq. (1).

The influence of VPD on $L_{\mathrm{V}} E$ also has the effect that the diurnal cycles of $Q^{*}$ and $L_{\mathrm{v}} E$ are out of phase due to its dependence on leaf temperature. $Q^{*}$ is primarily a function of incoming shortwave radiation and VPD of air temperature at the leaf surface. As a result, $Q^{*}$ and VPD peak at different times of the day. $Q^{*}$ peaks at maximum incoming shortwave radiation (local noon is at 11:30 UTC), and near-surface VPD times when air temperature peaks, which is around the time at which $Q^{*}=0(17: 00 \mathrm{UTC})$. The diurnal cycle of the sun implies there is a short period around 11:30 UTC when $Q^{*}$ does not change. On the contrary, air temperature increases almost linearly around 11:30 UTC due to the approximately constant $Q^{*}$, as does VPD. Therefore, peak values for $L_{\mathrm{v}} E$ are found between the moments of maximum $Q^{*}$ and of maximum VPD. For this dataset, the peak of $L_{\mathrm{V}} E$ is around 12:00 UTC for both clear and cloudy skies, although the peak for cloudy skies is less distinct due to the more fluctuating daily cycle of $Q^{*}$. Because $Q^{*}$ and $L_{\mathrm{v}} E$ are out of phase, the highest values for $L_{\mathrm{v}} E$ do not occur in the bin with the highest net radiation, but rather in the bin of $400-500 \mathrm{~W} \mathrm{~m}^{-2}$ (which roughly contains data from 11:00 UTC and after 12:00 UTC).

\subsubsection{Cloud-induced radiation perturbations and response by turbulent fluxes}

The short interval fluxes (1 min) of the double-beam laser scintillometer (DBLS) technique enable us to study the vegetation response to rapid radiation perturbations due to changes in cloud cover. The goal here is to illustrate this potential by discussing selected time series under changing cloud conditions during IOP 2 . The morning of IOP 2 was characterized by rapidly changing cloud conditions due to the overpass of a shallow cumulus cloud deck. A breakdown of the 1 min DBLS sensible heat flux in terms of contributions from turbulent exchange $\left(K_{\mathrm{T}}\right)$ and the measure for temperature fluctuations $\left(C_{T}^{2}\right)$ is given in Fig. 11. This figure also depicts, on the same axes, scaled time series of wind speed and PAR that can be regarded as proxies that fuel mechanically induced turbulence (wind speed) and buoyancy turbulence (radiation in general) as well as photosynthesis (PAR).

First of all, the 1 min DBLS fluxes of $H$ closely follow the cloud cover induced radiation changes, but with a time-lag of 45-120 s (Fig. 11a). This is similar to those reported by van Kesteren et al. (2013b). $H$ fluxes measured with EC techniques even when estimated over the relatively short interval of $10 \mathrm{~min}$, which is not a standard output, are not capable of 

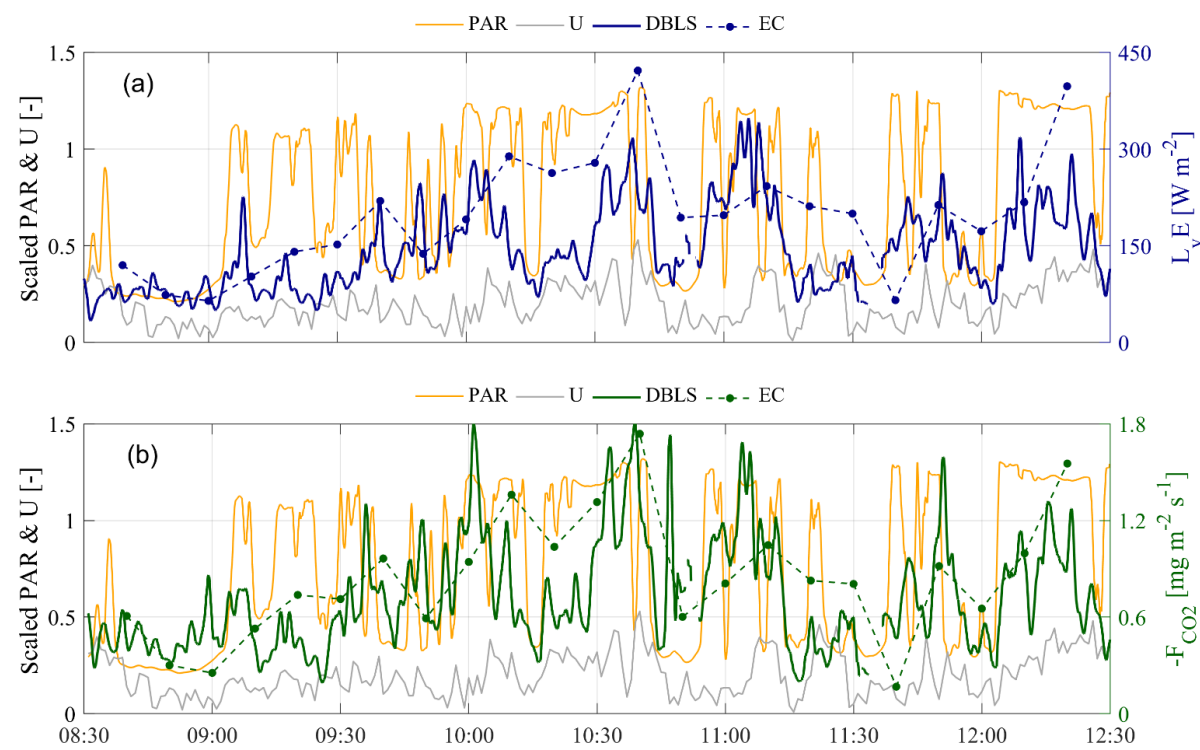

Figure 12. IOP 2 (15 June 2018) time-series of (a) latent heat fluxes (LvE) at 1 min intervals with a displaced-beam laser scintillometer (DBLS) and at 10 min intervals with an eddy covariance system (EC) combined with scaled time series of photosynthetically active radiation (PAR, scaled by $1500 \mu \mathrm{mol} \mathrm{m}{ }^{-2} \mathrm{~s}^{-1}$ ) and wind speed $\left(U\right.$, scaled by $\left.6 \mathrm{~ms}^{-1}\right)$. Panel (b) is the same as (a) but for the $\mathrm{CO}_{2}$ flux $\left(F_{\mathrm{CO}_{2}}\right)$.

capturing such rapid dynamic behaviour of the flux regime (Fig. 11a). The dynamic behaviour in the DBLS $H$ is mainly governed by fluctuations in $T$ expressed by $C_{T}^{2}$ (Fig. 11c) and to a lesser extent by changes in the exchange coefficient $K_{\mathrm{T}}$ (Fig. 11b). Note that is impossible to fully distinguish the three variables $H, K_{\mathrm{T}}$, and $C_{T}^{2}$ from each other as they are all interconnected, e.g. $K_{\mathrm{T}}$ is defined in terms of the Obukhov length $L$, which in turn depends on $H$ and $u_{*}$. Nevertheless, our high-time-resolution observations demonstrate that changes in PAR induce very fast responses of the transported quantity $T$ (Fig. 11c). Even in the absence of strong windinduced variations in $K_{\mathrm{T}}$, these $T$ variations lead to approximately similar dynamic behaviour of $H$. On top of this, the additional but smaller wind-induced fluctuations in $K_{\mathrm{T}}$ are also reflected in $H$ and lead to "noise" in the variability of $H$ compared to the cloud-induced on-off behaviour of PAR.

Next we examine how soon the fluxes of $\mathrm{H}_{2} \mathrm{O}$ and $\mathrm{CO}_{2}$ respond to the cloud induced radiation changes. Figure 12 demonstrates that there is indeed a fast response, and the 1 min resolution fluxes of $\mathrm{H}_{2} \mathrm{O}$ and $\mathrm{CO}_{2}$ allow us to precisely determine a delay time of approximately $2 \mathrm{~min}$ for the increases in $\mathrm{CO}_{2}$ uptake and transpiration of $\mathrm{H}_{2} \mathrm{O}$ relative to the changes in PAR. The delay is once again undetectable with the standard $30 \mathrm{~min}$ eddy covariance results (Fig. 12). This behaviour is in line with what was concluded about the state of the vegetation observed at leaf level (Sect. 3.1). As the vegetation is not water-stressed and is at a stage of development at which it is still actively growing, it will react rapidly to changes in radiation, i.e. it is in a radiationlimited regime. Under the conditions of our study, stomata appear to have reacted only slowly or remained constantly open because leaves were unstressed or reacting only slowly to cloud-induced changes. Moreover, the timescale of a lightinduced stomatal response (maximum values of $20 \mathrm{~min}$; Van Kesteren, 2013b) is normally larger than the timescale of most fluctuations in radiation. Our suggested explanation is that the 1 to 2 min delay time observed between radiation and turbulent fluxes is due to processes associated with the inertia of the leaf in addition to turbulent transport between the leaf and laser path due to, e.g. the small but not negligible storage of heat, $\mathrm{H}_{2} \mathrm{O}$ and $\mathrm{CO}_{2}$ in the canopy layer. However, we need further evidence to disentangle the separation in delays between $\mathrm{H}_{2} \mathrm{O}$ and $\mathrm{CO}_{2}$ fluxes.

\subsection{Sun-induced fluorescence (SIF) measurements: temporal variability}

Studying spatial and seasonal variabilities in ET during plant growth was one of the key goals of CloudRoots. To this end, we analysed SIF observations measured on time and on space. The top-of-canopy measurements of SIF were carried out in two ways: (i) diurnal courses from a single representative location were recorded from a stationary FLOX system, and (ii) mobile measurements covering several locations within a field were recorded from a FLOX system that was housed in a backpack. To ensure reproducible measurements, the two fibre optics of the system were attached to a gimbal and were placed with a movable tripod $2 \mathrm{~m}$ above ground. Diurnal curves were acquired on 7 May, 4 June, and 14 June (only morning hours due to cloudy conditions in afternoon); mobile measurements (with change of measurement locations during the day) on 6 and 26 June. As SIF measurements should be performed under clear-sky conditions only, records 

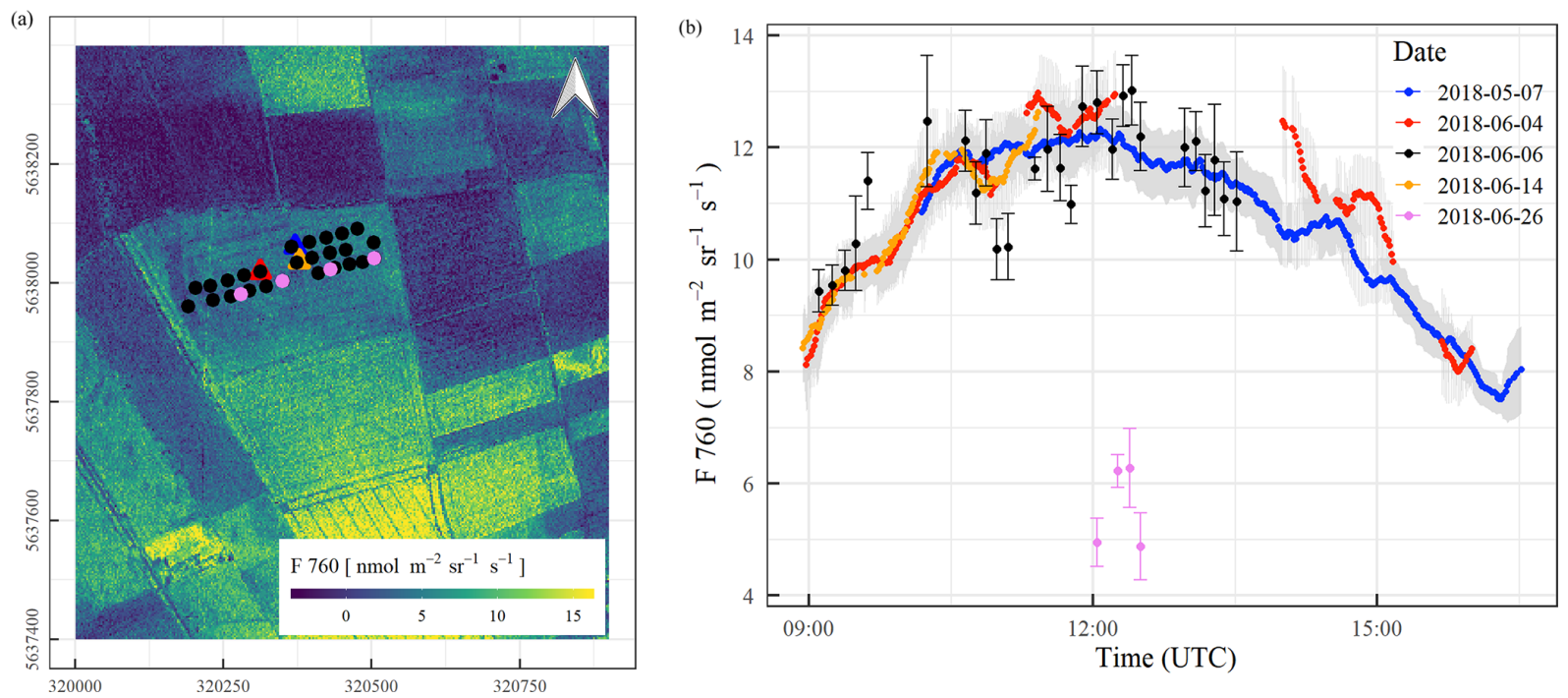

Figure 13. (a) Aerial map of $F_{760}$ on 26 June 2018 with measurement locations used to combine with mobile (circles) and stationary (triangles) measurements. (b) Diurnal changes in $F_{760}$ on different days of the campaign as 5 min measurement averages depicted in the same colours as observation locations in (a).

affected by clouds were carefully removed. Aerial maps of SIF were acquired with the high-resolution imaging spectrometer HyPlant. Figure 13a shows the aerial map of $F_{760}$ acquired on 26 June, suggesting homogeneous canopy properties within the winter wheat study field, while great differences can be seen between different fields. The same image identifies the FloxBox measurement locations in the same colour code that reconstruct the diurnal temporal variability of $F_{760}$ during the entire CloudRoots campaign in Fig. 13b.

Diurnal changes in photosynthetic activity are clearly visible in $F_{760}$. Measurements made at different locations generally follow the same diurnal pattern, especially within the period 7 May to 14 June, further confirming the hypothesis that ET spatial heterogeneity within the winter wheat field was small. The seasonal changes are also traced by $F_{760}$ : from 7 May until 14 June, the winter wheat canopy was photosynthetically active in a transition stage from booting (7 May) until grain filling (14 June), as is reflected by high SIF values. At the end of June, however, the canopy approached senescence and the reduction in photosynthesis was documented by greatly reduced fluorescence levels (see Fig. 13b, see pink values after 12:00 UTC). This photosynthesis reduction is also corroborated by the normalised difference vegetation index (NDVI), which was calculated as the normalized difference between far-red to red reflectance (see Supplement for details). The green dense canopy has a NDVI value close to 1 , and the decrease in NDVI is caused by the yellowish colour of the winter wheat canopy (see Fig. S2 at the Supplement).

\subsection{Connecting SIF and evapotranspiration flux at the landscape scale}

It is difficult to directly quantify spatial variations in the ET flux with the currently available in-situ equipment due to the necessity of installing a large number of measurement stations. Recently, some promising concepts have been published that exploit the relationship between SIF and plant water relations (Damm et al., 2018; Jonard et al., 2020). Following these concepts, we studied the connections between ET to regional measurements of SIF in two steps, which were recorded on this scale by the airborne sensor HyPlant (see Fig. 13a). First, to obtain an estimation of the spatial variability ET at CloudRoots, we used the $15 \mathrm{~km} \times 15 \mathrm{~km}$ map acquired by the HyPlant sensor on 26 June 2018 and a land use classification of the region (Lussem, 2018). ET cannot directly be measured, thus, it was predicted using different coefficients $\left(K_{\mathrm{c}}\right)$ that depend on the land use categories around CloudRoots. We define $K_{\mathrm{c}}$ as the ratio of ET over a particular crop relative to the ET of potential grass used as reference (Allen et al., 1998; Bogena et al., 2010). For this analysis, the regional land use map that consisted of 32 different land use classes was translated to a reduced classification scheme of 9 land use classes, which covered most of the vegetation types in the study region (Table 4). Roads were excluded from the analyses, as we assumed that their effect is negligible on the $15 \mathrm{~m} \times 15 \mathrm{~m}$ grid.

For the estimation of $K_{\mathrm{c}}$ coefficients to calculate ET, we used the plant developmental stage at the CloudRoots site at the end of June. For the main regional crops, namely sugar beet, winter wheat, winter barley, and potatoes, local measurements of evapotranspiration by EC towers were used. 
Table 4. Estimated $K_{\mathrm{c}}$ coefficients for different land use classes that are dominant in the study area. The land use classes were calculated using a more detailed land use classification that consisted of 32 classes. For this study several classes that have similar transpiration rates were combined.

\begin{tabular}{llll}
\hline & Land use class & $K_{\mathrm{c}}$ & Main surface types included \\
\hline 1. & Impervious & 0.0 & Roads, urban areas, industrial areas \\
2. & Bare soil & 0.2 & Bare fields, incl. harvested fields with \\
& & & rapeseed harvest residuals \\
3. & Needle forest & 0.5 & Managed spruce and pine forest \\
4. & Broadleaf forest & 0.7 & Broadleaf forest, scrubs \\
5. & Early crops (senescence) & 0.6 & Winter barley \\
6. & Early crops (approaching senescence) & 0.7 & Winter wheat \\
7. & Grassland & 0.8 & Natural grasslands, urban grasslands \\
8. & Late crops & 1.1 & Sugar beet, potato \\
9. & Maize & 1.2 & Maize \\
\hline
\end{tabular}

These data have been collected over several years and weekly averaged. This enabled us to compute $K_{\mathrm{c}}$ from measured and potential ET averaged over the last 2 weeks of June. In the particular cases of winter wheat and winter barley especially, the $K_{\mathrm{c}}$ coefficient changes rapidly at this time of the year, in extreme cases from 1.0 to 0.3 within 2 weeks, due to the onset of senescence. Therefore, the coefficients for these two crops shall be used with care. In absence of eddy covariance data, we calculates the characteristic values of $K_{\mathrm{c}}$ for each crop type and the developmental stage were taken from Allen et al. (1998). All estimated $K_{\mathrm{c}}$ coefficients for different crops can be found in Table 4. To estimate the ET over a specific area occupied by particular crop on a given day and time, the land use map was transferred to the map of $K_{\mathrm{c}}$ coefficients according to Table 4 and then multiplied by the potential ET, using the ET grass as a reference value (ETgrass), specific to that moment in time. Figure 14 shows the spatial variability of predicted ET for the IOP 3 inferred from the $K_{\mathrm{c}}$ coefficients and the value of potential grass reference averaged between 09:00 and 14:00 UTC. The area is a $1 \mathrm{~km} \times 1 \mathrm{~km}$ square, characterized by a mean of $5.76 \mathrm{mmol} \mathrm{m}^{-2} \mathrm{~s}^{-1}$ and a standard deviation of $1.86 \mathrm{mmol} \mathrm{m}^{-2} \mathrm{~s}^{-1}$. Figure 14 shows that this method can provide plausible information on the variability of ET at the sub-kilometre scale, and it points out to the need to introduce this sub-grid ET variability information in modelling studies. In the second step of the procedure, we compared this estimated ET to the SIF measurements $\left(F_{760}\right)$. Figure 15 shows the correlation between estimated ET and solar-induced fluorescence $F_{760}$ for 26 June (Julian day 177) for the different land covers. The correlation between mean $F_{760}$ values and predicted ET values is $R^{2}=0.61$ with larger ET and $F_{760}$ vales for crops and grass compared to the forest conditions. It is calculated from the comparison pixel by pixel of the SIF (Fig. 13a) and ET (Fig. 14). As the HyPlant overflight was carried out at noon in order to acquire the maximal SIF values and minimize the influence of changing sun angle, we also used the maximal value of ET grass, measured at midday on 26 June. The large

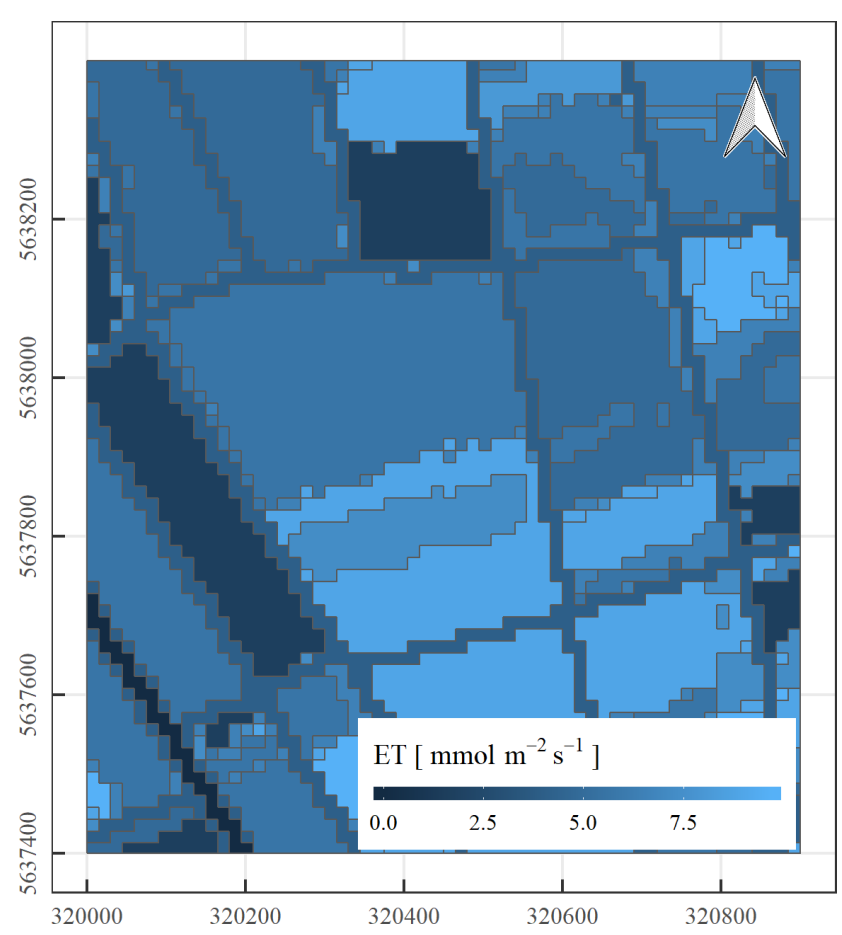

Figure 14. Spatial variability of evapotranspiration inferred from combining $K_{\mathrm{c}}$ coefficients with the value of potential grass reference ETgrass. The $x$ and $y$ axes represent the geographical coordinates of the CloudRoots site in metres $\left(50^{\circ} 52^{\prime} 09^{\prime \prime} \mathrm{N}, 6^{\circ} 27^{\prime} 01^{\prime \prime} \mathrm{E}\right)$.

range of values of ET, $F_{760}$, and $F_{687}$ from the different land use categories corroborate the large variability of ET around the CloudRoots field.

\subsection{Boundary layer integrated dynamics over heterogeneous landscapes}

To integrate and improve the interpretation of our observations, we used CLASS to model the cloudless day 7 May 2018 (IOP 1). Our specific aims, related to the scales 


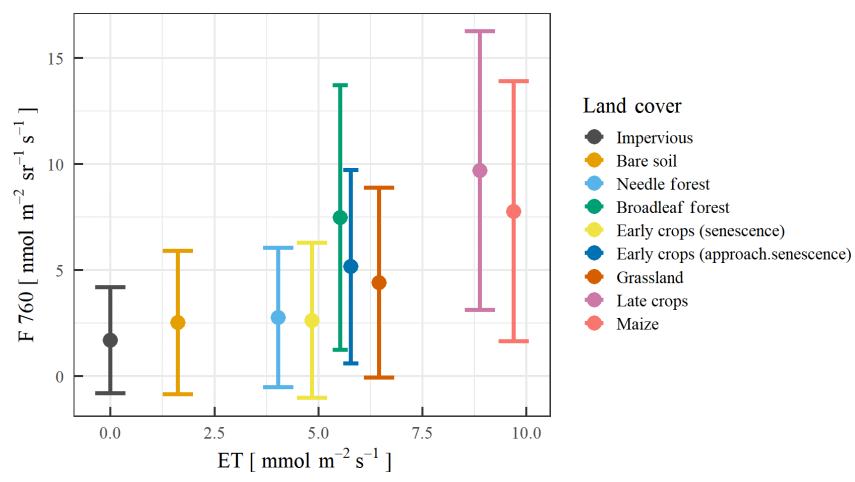

Figure 15. Relation between evapotranspiration (ET) and fluorescence $F_{760}$, including the standard deviation for the nine land use categories defined in Table 4 . The data were collected on 26 June 2018.

and processes under study, are (i) at leaf level to make use of the new constants in the mechanistic $A-g_{\text {s }}$ model obtained from the observations (Fig. 5 and Table 3), (ii) at a landscape scale to represent the sensible heat flux in a heterogeneous landscape, and (iii) to estimate the potential impact of advection (heat) on the diurnal evolution of surface and boundary layer variables. Table A2 summarizes all initial and boundary conditions, constrained by the observations, which are employed in the modelling of the surface and atmospheric variables. Figure 16 compares the model results with the surface and upper-air observations. Focusing first on Fig. 16a, we found that the modelled $H$ largely overestimates the observations taken at the CloudRoots. However, comparing our modelled $H$ with the estimate of the regional flux shown in Fig. 1b, we found a satisfactory agreement in terms of magnitude and diurnal variability between this regional observed flux and CLASS model calculation. Note that here, and compared to Table 4, we oversimplified the land surface into two categories: "bare soil" and "vegetated". To complete this evaluation, we show in Fig. S1 the impact of the optimized $A-g_{\text {s }}$ constants presented in Table 3 (CloudRoots) versus the default ones. Both the evolution of surface fluxes and boundary layer height are in better agreement with the observations. Similar impacts on how leaf processes (rice) can influence the meteorology were reported by Ikawa et al. (2018). There the boundary layer temperature changed by up to $0.5 \mathrm{~K}$ depending on the constants used in the leaf photosynthesis model.

Our explanation of the improved comparison between the observations and the CLASS results using the aggregated sensible heat flux is the following: in a heterogeneous landscape such as the location of CloudRoots (Fig. 1a), each surface type contributes its own latent and sensible heat fluxes. It is the landscape aggregate of heat fluxes (named regionally and shown with triangles in Fig. 16a and introduced in Fig. 1b) and more specifically the sensible heat flux that governs the boundary layer evolution in terms of height, po- tential temperature, specific humidity, and atmospheric constituents. Only by using this higher $H$ do we obtain satisfactory agreement with the observed boundary layer height evolution, which reaches its maximum values at around $1500 \mathrm{~m}$ in the afternoon (Fig. 8b). This further emphasizes that the $H$ measured with the EC instrument during CloudRoots is only representative of the specific measurement site (leaf and canopy scales). The landscape average is an aggregate of values of $H$ made up of the mosaic of surfaces as shown in Fig. 1. As a consequence, it is this composite $H$ rather than a local value of $H$ that is the main driver of the boundary layer development (boundary layer scales). With regard to ET, the model results are in good agreement with the local CloudRoots observations. This indicates the secondary and more local role played by ET in the dynamics of boundary layer development. For studies focusing on the regional values of ET, it will be necessary to calculate landscapescale aggregate following the same procedures as $H$, while for studies at the leaf and canopy scales the local observations of ET are representative. Focusing now on Fig. 16b, we found a satisfactory agreement between the modelled boundary layer height and the three independent observations made with three different instruments. In Fig. 16b, it is interesting to note that the ABL height $(75 \mathrm{~km})$ inferred by the radio sounding measurement collected more than $100 \mathrm{~km}$ from of the Cloud Roots site has values similar to those collected by the lidar located within a radius of $5 \mathrm{~km}$ from the CloudRoots site. We attribute these similar values to a boundary layer that is characterized by being spatially homogeneous and with a similar temporal evolution on the larger regional scale.

CLASS, besides solving the diurnal variability of the boundary layer dynamics and the state variables, offers the possibility of adding a large-scale contribution that represents the advection of heat and/or moisture (see Vilà-Guerau de Arellano et al., 2015). We have performed a sensitivity analysis to determine the role played by heat advection for the surface fluxes and the boundary layer development. In the specific case that is modelled on 7 May, we relate this advection of heat or moisture to the diurnal evolution of $H$ contrast between the measurement site and its adjacent fields, i.e. horizontal transport of heat, moisture, or momentum is driven by secondary circulations induced by the different thermal characteristics of the fields around the CloudRoots site (Fig. 1a). More specifically, we prescribe an advective heat contribution to represent the horizontal transport of heat due to the thermal variability of the surface conditions. This term follows an exponential function (Table A2 in Appendix A) with maximum positive values of advection equal to $0.9 \mathrm{~K} \mathrm{~h}^{-1}$ at midday. This advective term is imposed only on the mixed layer and not on the free troposphere. Figure 16 shows how this advection of warm air to the CloudRoots site influences the boundary layer height. Starting with $H$, warm advection leads to higher mixed-layer temperatures that reduce the gradient between the temperature at the surface and the atmosphere, and thus reduce $H$. We find an opposite effect 

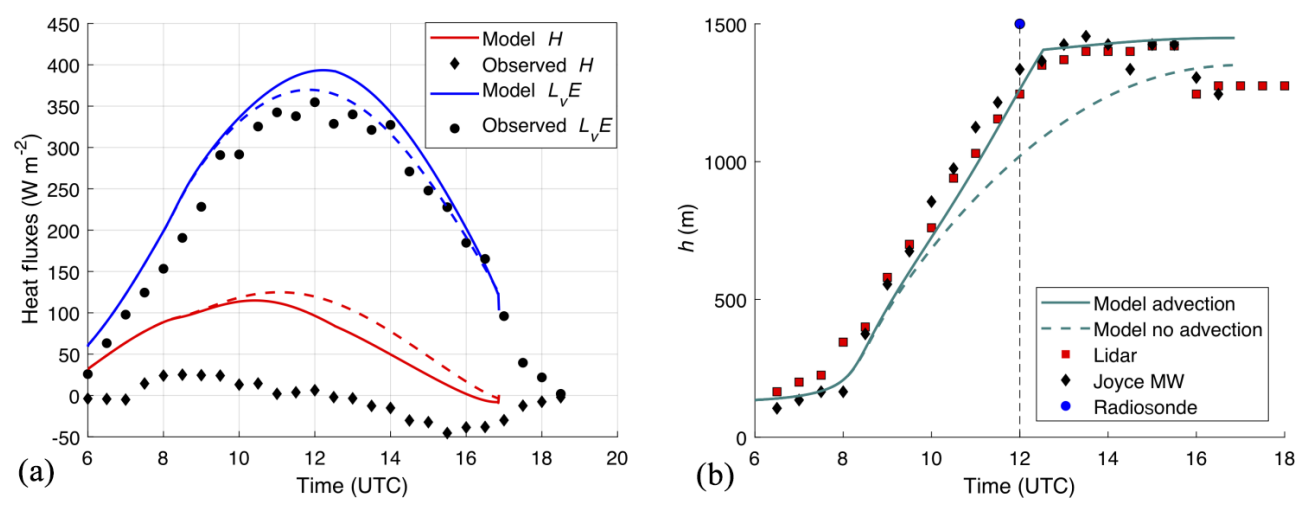

Figure 16. Comparison of the model and observed results of 7 May 2018: (a) surface fluxes and (b) boundary layer depth. The regional $H$, an aggregate that combines the vegetated and bare soil surfaces around the CloudRoots site as shown in Fig. 1b, is also included. For the boundary layer depth estimations, we used three different observational techniques. The lidar and microwave (MW) techniques were located at the JOYCE site facility. Solid and dashed lines represent the model results of surface fluxes and boundary layer height with and without imposing the advection of heat, respectively (Table A2), for completing the information on initial and boundary conditions.

on ET. The increase in temperature by advection of warm air leads to an increased atmospheric demand, and therefore enhances ET. With regard to the boundary layer height, we might suppose that a drop in $H$ would lead to a decrease of the boundary layer growth. However, the modelled boundary layer height displays the opposite behaviour. This is because the lower $H$ is partly offset by a decrease in the thermal inversion at the interface between the boundary layer and the free troposphere. Lower values of the difference in $\theta_{\mathrm{v}}$ between the free troposphere and the mixed layer enable boundary layer air parcels to be more easily transported into the free troposphere, resulting in faster growth of the boundary layer. This is because of the virtual potential temperature between the environment and the parcel is effectively reduced. The CLASS model results show that this process is more important than the decrease in $H$ at the surface, and it allows the boundary layer to grow deeper than in the numerical experiment in which the warm advection is omitted. These numerical sensitivity experiment analyses enable us to quantify how non-local processes, in particular the effects of the regional average $H$ and of warm advection, influence the observations at the measurement site.

\section{Discussion}

CloudRoots offers an integrated methodology that combines field experiments across spatial scales (from leaf to landscape) closely linked to the modelling of the diurnal variability of the soil-plant-atmosphere continuum. To frame the discussion and link all our observations at the various scales and modelling efforts, we present in Fig. 17 all the different estimates of ET obtained during the three IOPs, averaged between 09:00 and 14:00 UTC in order to avoid the morning and afternoon transitions. Plotted alongside the ET estimates, we showed the leaf-level measurement of $g_{\mathrm{sw}}$ to indicate the control of vegetation on canopy-level ET. The four instrumental techniques are sap flow, eddy covariance (EC), scintillometer (averaged over $30 \mathrm{~min}$ and $1 \mathrm{~min}$ ), ET inferred by the profile lift measurements, and ET infrared from the SIF observations. The ET modelled by CLASS is also included for IOP 1.

In comparing ET from the three IOPs, we find significant differences in magnitude from different techniques. In general, the highest values of ET are observed during IOP 1 . The three IOPs were characterized by differences in the stages of growth, from very active vegetation to senescent vegetation, and influenced by a range of weather conditions: IOP 1 cloudless, IOP 2 scattered and thick clouds, and IOP 3 shallow cumuli. It is surprising that the decay in the vegetation activity as quantified by the measurements of leaf conductivity (Fig. 3d, e, f) is less evident in differentiating IOP 3 (senescent stage) from the more active vegetation at IOP 1 and 2. Furthermore, we observed, moving from IOP 1 to IOP 3, a much stronger decline in $g_{\mathrm{sw}}$, suggesting that stomatal closure compensated for increased atmospheric moisture demand.

Several conclusions can be drawn from this intercomparison of ET observations using different techniques. Firstly, we might expect that the EC and scintillometer measurements, both with larger footprint and the inclusion of the soil evaporation contribution, show a net total ET that is similar to or higher than that obtained by the sap flow measurements. Secondly, we observed a far more pronounced response in declining $g_{\mathrm{sw}}$ compared to all ET measurements. These results point to the need to more accurately measure the leaf energy balance to take the penetration of radiation in the canopy under clear and cloudy conditions into account. This would also require a revision of scaling procedure from the leaf to the canopy level. Secondly, it is known that the EC flux measurements normally underestimate the sensible and latent heat 

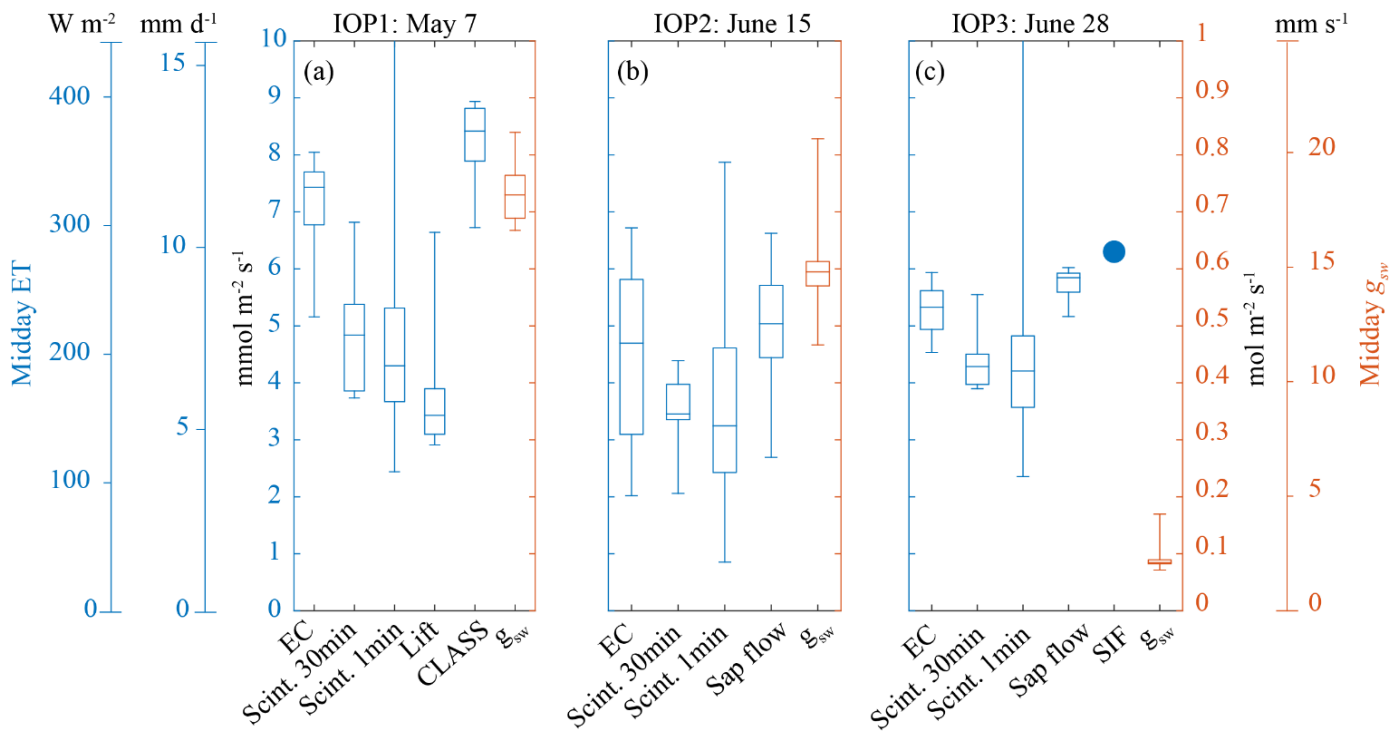

Figure 17. Summary of midday evapotranspiration collected using different instrumental techniques during (a) IOP 1, (b) IOP 2, and (c) IOP 3. ET fluxes (left $y$ axis) and $g_{\mathrm{sw}}$ (right $y$ axis) reflect the period from 09:00 to 14:00 UTC. Box plots denote the variability in 30 min measurement intervals, except for the 1 min scintillometer measurements. The central mark of each box indicates the median, and the bottom and top edges of the box indicate the 25 th and 75 th percentiles, respectively. The acronyms are eddy covariance (EC), scintillometer (Scint) with $30 \mathrm{~min}$ and $1 \mathrm{~min}$ averages, ET inferred from the lift profiles (Lift), sap flow, ET calculated with the CLASS model, and ET inferred from the sun-induced fluorescence (SIF).

fluxes because the EC flux measurements filter out the low frequencies (Foken et al., 2008; Gao et al., 2017). This underestimation is difficult to determine, but as a first guess and related to Fig. 17, the underestimation might range between $10 \%$ and $15 \%$.

Although the contribution of soil evaporation is small compared to plant transpiration due to the high vegetation cover, we need to stress that EC and scintillometer observations are similar to or smaller than the ET observed or inferred from the other techniques (Fig. 17). This highlights the difficulty of estimating ET due to the need to include and quantify the contributions of the four fundamental processes: soil evaporation, upscaled leaf transpiration, evaporation related to the sap flow and the two non-local processes, entrainment of dry air, and horizontal advection of heat and moisture. Here, the modelling of ET, taking into account for and integrating all these processes, enables us to discriminate among these processes and calculate the budget of ET as a function of these local and non-local contributions. In that respect, the CLASS model is a tool capable of efficiently combining observations and model results that integrate surface and boundary layer dynamics. The averaged modelled ET is at the higher range of the ET observed estimations during IOP 1.

With respect to the differences between the $1 \mathrm{~min}$ and 30 min series measured by the scintillometer, their median is very similar in the three IOPs. However, differences become larger at smaller timescales due to the non-steadiness of ET under the presence of clouds. Here, the $1 \mathrm{~min}$ flux calculated from the scintillometer can capture the rapid and large fluctuations by clouds (Fig. 12) and the maximum values in particular. In order to obtain more definitive conclusions on how ET varies under cloud conditions, we need to analyse other situations characterized by different diurnal cloud cycles in more detail and systematically relate ET to key cloud characteristics such as the cloud optimal depth to determine how cloud thickness influences ET and the timescale of the cloud passage.

Regarding the quantification of the different processes contributing to ET, Fig. 9 illustrates the need to continue to test analytical techniques to identify the individual contributions of soil and plants to determine the diurnal ET budget. A possibly useful tracer would be the stable isotopic composition of water vapour and carbon dioxide (Lee et al., 2009; Griffis 2013) and, combined with isotope signals, for modelling the surface and boundary layer dynamics with the carbon and water exchanges. To further discriminate between soil and plant sources and sinks under unsteady conditions due to radiation and dynamic perturbations by cloud shading, these high-frequency stable isotope measurements should go beyond the typical average time of eddy covariance $(30 \mathrm{~min}$ ). As van Kesteren et al. (2013) showed and is further corroborated in this work, the scintillometer technique combined with high-frequency observations of $\mathrm{H}_{2} \mathrm{O}$ and $\mathrm{CO}_{2}$ enable us to quantify the response time of ET and $\mathrm{CO}_{2}$ assimilation to these intermittent radiation fluctuations or cloud flecks (Kaiser et al., 2018). 
Finally, the integration of all processes in the CLASS model shows the challenges in interpreting the measurements taken at the sub-kilometre scales and adequately representing the surface turbulent fluxes. Although the measurements indicate that the day selected for the modelling displayed a very homogeneous boundary layer depth over an area with a radius of $100 \mathrm{~km}^{2}$, the sensible heat flux measured at the CloudRoots facility was not representative of it. Therefore, we recommend extending the number of stations by means of a multi-tower approach that would also include detailed observations of the soil and plant conditions. In addition to obtaining a more representative field sensible heat flux that is better related to the development of the boundary layer, a denser network of spatial observation stations is also necessary to estimate the role of hectometre-scale heterogeneityinduced circulations and their relationships with the local advection of heat and moisture more accurately (Mauder et al., 2010).

\section{Conclusions}

Our main findings, organized from the smaller to the larger scales observed and modelled, are summarized as follows:

At leaf scale, we find that stomatal conductance and gross primary production decrease in line with the increasing senescence of the plant. The tiller-level measurements of the sap flow are virtually constant throughout the growing period. Underlying causes need to be further investigated under controlled conditions. The successful modelling of the leaf stomatal conductance and the photosynthesis assimilations required the relevant constants used in the mechanistic model $\left(A-g_{\mathrm{s}}\right)$ in the field to be measured. Modelled leaflevel photosynthesis compares better with the measurements during the mature growing period than during senescence. For future field experiments, we recommend including leaflevel measurements in meteorological campaigns to improve calculations related to the water-carbon leaf and canopy exchanges.

At canopy scale, the high-frequency vertical profiles measured in and above the canopy - of wind speed, potential temperature, specific humidity, and carbon dioxide prove to be very valuable in obtaining profiles of gross primary production in the canopy and as a function of height. By inverting these observed profiles, we obtain an estimate of the contributions of soils and plants to the net evapotranspiration and $\mathrm{CO}_{2}$ ecosystem exchange. The validation against individual measurements of these components gives better results for the net ecosystem exchange than those for the net evapotranspiration. We argue that for evapotranspiration the dependence on temperature and water vapour deficit plays a more important role than for $\mathrm{CO}_{2}$ assimilation, the latter being mainly controlled by the partitioning between direct and diffuse radiation.
Under cloud conditions, we show that the perturbation by clouds of direct and diffuse radiation create large fluctuations in evapotranspiration and the $\mathrm{CO}_{2}$ assimilation with opposite signs for evapotranspiration and $\mathrm{CO}_{2}$ exchange. A cloudy boundary layer reduces evapotranspiration, whereas it enhances plant assimilation of $\mathrm{CO}_{2}$. The 1 min turbulent fluxes acquired by the scintillometer demonstrate the relevance of flux measurements observed at higher frequencies for improving quantification of the impact of clouds on the photosynthetically active radiation. With these fast turbulent fluxes, we quantify delays of the turbulent fluxes with respect to the photosynthetically active radiation. These delays are on the order of minutes. Comparing these 1 min flux estimates with the standard 30 min average measured with the eddy covariance technique, we find a lower median and a large increase in the variability of the net evapotranspiration. This information can be useful in determining the impact of rapid fluctuations driven by the impact of clouds on evapotranspiration and its impact on the closure of the surface energy balance.

At landscape and boundary layer integrated scales, the modelled sensible heat flux correlates better with the areaweighted average flux than the local flux estimates. The areaweighted flux integrates in a simple manner a composite of bare soil and vegetated surfaces at regional scale (kilometres). This aggregate regional flux is representative of an area that is larger than the CloudRoots site $(100 \mathrm{~m} \times 100 \mathrm{~m})$. Therefore, a model setup that represents the boundary layer evolution well only needed to be informed by the areaweighted average of two main surface types, bare soil, and vegetated areas. The variations of ET due to surface heterogeneity were also measured and inferred from airborne suninduced fluorescence observations. Our findings corroborate the large heterogeneity of ET at the sub-kilometre scales with values ranging from forest (about $2.5 \mathrm{mmol} \mathrm{m}^{-2} \mathrm{~s}^{-1}$ ) to late crops such as potato or sugar beet $\left(8-10 \mathrm{mmol} \mathrm{m}^{-2} \mathrm{~s}^{-1}\right)$.

The comparison of all the ET measurements at the various scales show that there are still large differences in observing ET among the different observing techniques, the modelling of ET and their relation to stomatal aperture during the entire growing season. These ET observations do not show a clear pattern related to the scale at which they were measured.

The modelling and scale integration of this comprehensive observational dataset enables us to study the carbon and water exchange at leaf, canopy, and landscape levels. It also allows us to quantify how horizontal advection of heat within the mixed layer influences the surface fluxes and the growth of the atmospheric boundary layer. We show, for instance, that the horizontal advection of heat leads to deeper boundary layer depths. This numerical experiment thus paves the way to more complete modelling studies, for instance using largeeddy simulation numerical experiments, on how the surface and the overlaying atmosphere interact on sub-diurnal and sub-kilometre scales. 


\section{Appendix A: Construction of light and radiation response curves under clear and cloudy conditions}

For the construction of the light and radiation response curves in Fig. 10, the data were divided into bins of PAR and $Q^{*}$. For Fig. 10a, we divided the data points in bins of incoming total PAR. Each bin covers a range of $50 \mathrm{Wm}^{-2}$, starting at $0-50 \mathrm{Wm}^{-2}$ and presumably ending at around 350 $400 \mathrm{Wm}^{-2}$ (maximal intensity for incoming direct PAR). For Fig. 10b and the variable $Q^{*}$, each bin covers a range of $100 \mathrm{~W} \mathrm{~m}^{-2}$, starting at -200 to $100 \mathrm{~W} \mathrm{~m}^{-2}$ for cloudy skies and at 0 to $100 \mathrm{~W} \mathrm{~m}^{-2}$ for clear skies. In both figures, for each data point the diffuse fraction of PAR is determined by combining measurements of incoming total PAR and incoming diffuse PAR. Subsequently, a data point is labelled "clear" for diffuse fractions $<0.3$ and labelled "cloudy" for diffuse fractions $>0.8$. We choose these boundaries to balance a distinct difference between clear and cloudy skies with a large enough sample size for each bin. For clear skies, the first two bins are missing. This is due to the fact that under clear skies low levels of $Q^{*}$ are the result of the sun being close to the horizon, and as a result solar radiation has to travel a long distance through the atmosphere before reaching the surface. In those cases, most of the solar radiation reaches the surface as diffuse radiation due to Rayleigh scattering and scattering by aerosols, and therefore does not meet the criteria to be labelled "clear". For cloudy skies, bins are missing for high levels of $Q^{*}$. Clouds attenuate solar radiation through absorption and backscattering, and thereby reduce $Q^{*}$ to a level lower than it would be for a clear sky.
Table A1. Management activities on the test site over the winter wheat cultivation cycle before, during, and after the observation period of the CloudRoots campaign.

\begin{tabular}{|c|c|c|}
\hline Date & Management & Product \\
\hline 25 Oct 2018 & sowing crop seeds (weight of seeds) & $\begin{array}{l}156 \mathrm{~kg} \mathrm{ha}^{-1} \text { winter } \\
\text { wheat (Premio) }\end{array}$ \\
\hline 8 Mar 2018 & fertilization & $81.6 \mathrm{~kg} \mathrm{Nha}^{-1}$ \\
\hline 9 Apr 2018 & herbicide treatment & $200 \mathrm{~g} \mathrm{ha}^{-1}$ Broadway \\
\hline 9 Apr 2018 & herbicide treatment & $1 \mathrm{~L} \mathrm{ha}^{-1} \mathrm{CCC} 720$ \\
\hline 22 Apr 2018 & fertilization & $39.2 \mathrm{~kg} \mathrm{Nha}^{-1}$ \\
\hline 2 May 2018 & fungicide treatment & $1 \mathrm{~L} \mathrm{ha}^{-1}$ Capalo \\
\hline 2 May 2018 & fungicide treatment & $0.3 \mathrm{~L} \mathrm{ha}^{-1}$ Corbel \\
\hline 2 May 2018 & herbicide treatment & $0.3 \mathrm{~L} \mathrm{ha}^{-1} \mathrm{CCC} 720$ \\
\hline 16 May 2018 & fertilization & $50 \mathrm{~kg} \mathrm{Nha}^{-1}$ \\
\hline 19 May 2018 & fungicide treatment & 1.5 $\mathrm{L} \mathrm{ha}^{-1}$ Adexar \\
\hline 19 May 2018 & fungicide treatment & $0.5 \mathrm{~L} \mathrm{ha}^{-1}$ Diamant \\
\hline 19 May 2018 & insecticide treatment & $0.3 \mathrm{~L} \mathrm{ha}^{-1}$ Bulldock \\
\hline 16 Jul 2018 & harvesting & winter wheat, $92 \mathrm{dt} \mathrm{ha}^{-1}$ \\
\hline 19 Jul 2018 & straw pressed and removed & \\
\hline 25 Aug 2018 & ploughing & \\
\hline 18 Sep 2018 & harrowing & \\
\hline
\end{tabular}


Table A2. Initial and boundary conditions prescribed in CLASS to reproduce IOP 1 (7 May 2018).

\begin{tabular}{|c|c|c|}
\hline \multicolumn{3}{|l|}{ Mixed-layer model parameters } \\
\hline Parameter (units) & Value & Source \\
\hline Time steps (s) & 60 & - \\
\hline Runtime (s) & 50400 & - \\
\hline Residual-layer starting height $\left(z_{i 0}\right)$ & 135 & Joyce microwave \\
\hline Surface layer top height (m) & 1400 & radiosonde \\
\hline Surface pressure $(\mathrm{Pa})$ & 100600 & EC pressure gauge \\
\hline Large-scale wind divergence $\left(\mathrm{s}^{-1}\right)$ & 0 & default \\
\hline$f_{\mathrm{c}}\left(\mathrm{m} \mathrm{s}^{-1}\right)$ & $1.10^{-4}$ & latitude \\
\hline Coriolis parameter $(-)$ & 0.2 & default \\
\hline \multicolumn{3}{|l|}{ Potential temperature } \\
\hline Initial mixed-layer temperature $(\mathrm{K})$ & 286.2 & profile data and radiosonde \\
\hline Jump in potential temperature from boundary layer to free troposphere $(\mathrm{K})$ & 4 & radiosonde \\
\hline Jump in potential temperature from boundary layer to residual layer $(\mathrm{K})$ & 4.4 & radiosonde \\
\hline Free troposphere lapse rate for potential temperature $\left(z_{i 0}<1400 \mathrm{~m}\right)(\mathrm{K})$ & $4.9 \times 10^{-3}$ & radiosonde \\
\hline Free troposphere lapse rate for potential temperature $\left(z_{i 0}>1400 \mathrm{~m}\right)(\mathrm{K})$ & $6.2 \times 10^{-3}$ & radiosonde \\
\hline Advection of heat into the mixed layer $\left(\mathrm{K} \mathrm{s}^{-1}\right)$ & & $2.5 \times 10^{-4} e^{-\frac{(t[\mathrm{UTC}]-12)^{2}}{5}}$ \\
\hline \multicolumn{3}{|l|}{ Specific humidity } \\
\hline Initial function mixed-layer specific humidity $\left(\mathrm{kg} \mathrm{kg}^{-1}\right)$ & & $0.0067-0.0004(t[\mathrm{UTC}]-6.5)$ \\
\hline Residual-layer lapse rate for specific humidity $\left(\mathrm{kg} \mathrm{kg}^{-1} \mathrm{~m}^{-1}\right)$ & $-1.4 \times 10^{-3}$ & radiosonde \\
\hline Free troposphere lapse rate for specific humidity $\left(z_{i 0}<1400 \mathrm{~m}\right)\left(\mathrm{kg} \mathrm{kg}^{-1} \mathrm{~m}^{-1}\right)$ & $-2.7 \times 10^{-6}$ & radiosonde \\
\hline Free troposphere lapse rate for specific humidity $\left(z_{i 0}>1400 \mathrm{~m}\right)\left(\mathrm{kg} \mathrm{kg}^{-1} \mathrm{~m}^{-1}\right)$ & $-9.0 \times 10^{-6}$ & radiosonde \\
\hline Advection of specific humidity into the mixed layer $\left(\mathrm{kg} \mathrm{kg}^{-1} \mathrm{~m}^{-1}\right)$ & 0 & default \\
\hline \multicolumn{3}{|l|}{ Carbon dioxide } \\
\hline Initial mixed-layer $\mathrm{CO}_{2}\left(\mu \mathrm{molCO} \mathrm{mol}^{-1}\right.$ air $)$ & 400 & profile measurements \\
\hline Jump in $\mathrm{CO}_{2}$ at the inversion layer $\left(\mu \mathrm{molCO} \mathrm{mol}^{-1}\right.$ air) & -44 & profile measurements \\
\hline Free troposphere lapse rate for $\mathrm{CO}_{2}\left(\mu \mathrm{molCO}_{2} \mathrm{~mol}^{-1}\right.$ air m$\left.{ }^{-1}\right)$ & 0 & default \\
\hline Advection of $\mathrm{CO}_{2}$ into the mixed layer $\left(\mu \mathrm{molCO}{ }_{2} \mathrm{~mol}^{-1}\right.$ air s $\left.{ }^{-1}\right)$ & 0 & default \\
\hline \multicolumn{3}{|l|}{ ( } \\
\hline Initial wind speed in the longitudinal direction $\left(\mathrm{m} \mathrm{s}^{-1}\right)$ & 1.75 & profile measurements \\
\hline Jump in longitudinal wind velocity at the inversion layer $\left(\mathrm{m} \mathrm{s}^{-1}\right)$ & 3 & profile measurements \\
\hline Free troposphere lapse rate for longitudinal wind velocity $\left(\mathrm{m} \mathrm{s}^{-1} \mathrm{~m}^{-1}\right)$ & $-1.8 \times 10^{-3}$ & profile measurements \\
\hline Advection of longitudinal wind into the mixed layer $\left(\mathrm{m} \mathrm{s}^{-1} \mathrm{~s}^{-1}\right)$ & 0 & default \\
\hline Wind speed in the latitudinal direction $\left(\mathrm{m} \mathrm{s}^{-1}\right)$ & 0 & default \\
\hline Jump in latitudinal wind velocity at the inversion layer $\left(\mathrm{m} \mathrm{s}^{-1}\right)$ & 0 & default \\
\hline Free troposphere lapse rate for latitudinal wind velocity $\left(\mathrm{m} \mathrm{s}^{-1} \mathrm{~m}^{-1}\right)$ & 0 & default \\
\hline Advection of latitudinal wind into the mixed layer $\left(\mathrm{m} \mathrm{s}^{-1} \mathrm{~s}^{-1}\right)$ & 0 & default \\
\hline Roughness length for momentum (m) & 0.02 & canopy height \\
\hline Roughness length for scalars (m) & 0.002 & canopy height \\
\hline \multicolumn{3}{|l|}{ Geographical coordinates and radiation } \\
\hline Latitude $\left(^{\circ}\right)$ & 50.9 & geographical location \\
\hline Longitude $\left({ }^{\circ}\right)$ & 6.4 & geographical location \\
\hline Julian day of year (d) (7 May 2018) & 127 & data selected case \\
\hline Start time (hours UTC) & 6.0 & - \\
\hline Cloud cover fraction $(-)$ & 0 & camera \\
\hline Cloud-top radiative divergence $\left(\mathrm{W} \mathrm{m}^{-2}\right)$ & 0 & camera \\
\hline
\end{tabular}


Table A2. Continued.

\begin{tabular}{|c|c|c|}
\hline \multicolumn{3}{|l|}{ Mixed-layer model parameters } \\
\hline Parameter (units) & Value & Source \\
\hline \multicolumn{3}{|l|}{ Soil } \\
\hline Soil moisture top soil layer $\left(\mathrm{m}^{3} \mathrm{~m}^{-3}\right)$ & 0.177 & soil measurements \\
\hline Soil moisture deep soil layer $\left(\mathrm{m}^{3} \mathrm{~m}^{-3}\right)$ & 0.286 & soil measurements \\
\hline Vegetation cover fraction $(-)$ & 0.98 & visual inspection, camera \\
\hline$T$ top soil layer $(\mathrm{K})$ & 285.5 & soil measurements \\
\hline$T$ deep soil layer $(\mathrm{K})$ & 284 & soil measurements \\
\hline Clapp and Hornberger parametre $a(-)$ & 0.219 & soil composition \\
\hline Clapp and Hornberger parametre $b(-)$ & 5.3 & soil composition \\
\hline Clapp and Hornberger parametre $p(-)$ & 4 & soil composition \\
\hline Saturated soil conductivity for heat (-) & $3.56 \times 10^{-6}$ & soil composition \\
\hline Saturated volumetric water content (-) & 0.472 & soil composition \\
\hline Field capacity volumetric water content (-) & 0.3 & soil composition \\
\hline Wilting point volumetric water content $(-)$ & 0.154 & soil composition \\
\hline Parameter to calculate top layer soil moisture tendency (-) & disabled & soil composition \\
\hline Parameter to calculate top layer soil moisture tendency $(-)$ & disabled & soil composition \\
\hline LAI $(-)$ & 4.5 & on-site determination \\
\hline Correction factor transpiration for VPD for high vegetation (-) & 0 & vegetation height \\
\hline Minimum soil resistance $\left(\mathrm{s} \mathrm{m}^{-1}\right)$ & 50 & default \\
\hline Albedo $(-)$ & 0.2 & radiation measurements \\
\hline Surface temperature $(\mathrm{K})$ & 286.3 & profile measurements \\
\hline Thickness of water layer on wet vegetation (m) & 0.0002 & default \\
\hline Equivalent water layer depth for wet vegetation (m) & 0.0001 & on-site observations \\
\hline Thermal conductivity skin layer & 5.9 & default \\
\hline \multicolumn{3}{|l|}{$A-g_{\mathrm{s}}$ model parameters } \\
\hline $\mathrm{CO}_{2}$ compensation concentration $\left(\mathrm{mg} \mathrm{m}^{-3}\right)$ & 68.5 & $\mathrm{C} 3$ reference value \\
\hline Function parameter to calculate $\mathrm{CO}_{2}$ compensation (-) & 1.5 & $\mathrm{C} 3$ reference value \\
\hline Mesophyll conductance $\left(\mathrm{m} \mathrm{s}^{-1}\right)$ & 10.0 & leaf gas exchange \\
\hline Maximum assimilation rate for $\mathrm{CO}_{2}$ at $298 \mathrm{~K}\left(\mathrm{mg} \mathrm{m}^{-2} \mathrm{~s}^{-1}\right)$ & 1.926 & leaf gas exchange \\
\hline Reference temperature to calculate mesophyll conductance (K) & 278 & $\mathrm{C} 3$ reference value \\
\hline Reference temperature to calculate mesophyll conductance $(\mathrm{K})$ & 301 & $\mathrm{C} 3$ reference value \\
\hline Function parameter to calculate maximal primary productivity (-) & 2.0 & $\mathrm{C} 3$ reference value \\
\hline Reference temperature to calculate maximal primary productivity $(\mathrm{K})$ & 281 & $\mathrm{C} 3$ reference value \\
\hline Reference temperature to calculate maximal primary productivity $(\mathrm{K})$ & 311 & $\mathrm{C} 3$ reference value \\
\hline Maximum value of the ratio between the leaf and external (-) & 0.89 & $\mathrm{C} 3$ reference value \\
\hline Regression coefficient to calculate the ratio between the leaf and external $\mathrm{CO}_{2}$ concentration (-) & 0.07 & $\mathrm{C} 3$ reference value \\
\hline Initial low-light conditions use efficiency for $\mathrm{CO}_{2}\left(\mathrm{mg} \mathrm{J}^{-1}\right)$ & 0.0053 & leaf gas exchange \\
\hline Extinction coefficient PAR $\left(\mathrm{m} \mathrm{m}^{-1}\right)$ & 0.7 & C3 reference value \\
\hline Minimum cuticular conductance $\left(\mathrm{mm} \mathrm{s}^{-1}\right)$ & $2.5 \times 10^{-4}$ & $\mathrm{C} 3$ reference value \\
\hline
\end{tabular}


Data availability. All CloudRoots observations are archived at https://www.tr32db.uni-koeln.de (last access: 21 August 2020), using the search term "cloudroots". Only CRC/TR32 participants are allowed to apply for an account. Please contact the TR32DB admin for further information. The CLASS model (Python and Fortran versions) is freely available at http://classmodel.github.io/ (last access: 21 August 2020).

Supplement. The supplement related to this article is available online at: https://doi.org/10.5194/bg-17-4375-2020-supplement.

Author contributions. JVGdA designed the CloudRoots study and approach. $\mathrm{OH}$ and $\mathrm{AG}$ designed and coordinated the CloudRoots field experiment. The individual measurements were gathered by $\mathrm{OH}$ (scintillometer); HB (stomatal aperture/photosynthesis); AK, AG, and PN (microlysimeters and elevator profiles); ML (sap flow); MM and DE (SIF); and TR, GA, NB, and YR (stable carbon and water vapour isotopes). HdB integrated the observations to be connected with the modelling efforts. GdG, GM, HdB, and JVGdA performed the numerical experiments with CLASS. PN and JVGdA wrote the paper with key contributions from all the authors: $\mathrm{OH}$, HdB, KvD, DE, GdG, AK, ML, MM, GMG, AFM, UR, TR, and GA.

Competing interests. The authors declare that they have no conflict of interest.

Acknowledgements. The authors wish to thank Bernhard Pospichal and Tobias Marke for contributing measurements on boundary layer properties. These data were provided by the Jülich Observatory for Cloud Evolution (JOYCE-CF), a core facility funded by DFG via grant DFG LO 901/7-1. Hubert Hüging and Huu Thuy Nguyen from the INRES Crop Science Group of Bonn University for operating the sap-flow equipment.

Financial support. This study was financed by the Deutsche Forschungsgemeinschaft (DFG) Collaborative Research Centre 32 (TR32) "Patterns in Soil-Vegetation-Atmosphere System". The contribution of AG and deployment of the profile elevator, microlysimeter and part of the isotope measurements were financed by the German Federal Ministry of Education and Research (BMBF) within the framework of the project "IDAS-GHG" (Grant: FKZ 01LN1313A). Airborne acquisition and data analysis with the HyPlant sensor were financed by the European Space Agency (ESA) in the frame of the FLEXSense campaign (ESA Contract No. ESA RFP/3-15477/18/NL/NA). The contribution of PN to the analysis were financed by the European Space Agency (ESA) within the project PhotoProxy (Grant. ESA RFP/3-15506/18/NL/NF). The ancillary hardware and its maintenance were supported by TERENO (https://www.tereno.net, last access: 21 August 2020). These data were provided by the Jülich Observatory for Cloud Evolution (JOYCE-CF), a core 40 facility funded by DFG via grant DFG LO 901/7-1.
The article processing charges for this open-access publication were covered by the Max Planck Society.

Review statement. This paper was edited by Ivonne Trebs and reviewed by Dennis Baldocchi and one anonymous referee.

\section{References}

Allen, R., Pereira, L., Raes, D., and Smith, M.: Crop evapotranspiration: Guidelines for computing crop water requirements. Food and Agriculture Organization of the U.N. Irrigation and Drainage Paper 56, 300 pp., 1998.

Alonso, L., Gómez-Chova, L., Vila-Francés, J., Amorós-López, J., Guanter, L., Calpe, J., and Moreno, J.: Improved Fraunhofer Line Discrimination method for vegetation fluorescence quantification, IEEE Geosci. Remote Sens. Lett., 5, 620-624, 2008.

Baker, J. M. and van Bavel, C. H.: Measurement of mass flow of water in the stems of herbaceous plants, Plant Cell Environ., 9, 777-782, 1987.

Bogena, H., Herbst, M., Huisman, J., Rosenbaum, U., Weuthen, A., and Vereecken, H.: Potential of Wireless Sensor Networks for Measuring Soil Water Content Variability, Vadose Zone J., 9, 1002-1013, 2010.

Boussetta, S., Balsamo, G., Beljaars, A., Panareda, A., Calvet, J.C., Jacobs, C., van den Hurk, B., Viterbo, P., Lafont, S., Dutra, E., Jarlan, L., Balzarolo, M., Papale, D., and van der Werf, G.: Natural land carbon dioxide exchanges in the ECMWF Integrated Forecasting System: Implementation and offline validation, J. Geophys. Res.-Atmos., 118, 5923-5946, 2013.

Campbell, P., Huemmrich, K., Middleton, E., Ward, L. A., Julitta, T., Daughtry, C. S. T., Burkart, A., Russ, A. L., and Justas, W. P.: Diurnal and Seasonal Variations in Chlorophyll Fluorescence Associated with Photosynthesis at Leaf and Canopy Scales, Remote Sens., 11, 488-515, 2019.

Damm, A., Paul-Limoges E., Haghighi E., Simmer C., Morsdorf F., Schneider F. D., van der Tol C., Migliavacca M., and Rascher U.: Remote sensing of plant-water relations: An overview and future perspectives, J. Plant Physiol., 227, 3-19, https://doi.org/10.1016/j.jplph.2018.04.012, 2018.

Dengel, S. and Grace, J.: Carbon dioxide exchange and canopy conductance of two coniferous forests under various sky conditions, Oecologia, 164, 797-808, 2010.

Drewry, D. T. Kumar, P., and Long, S. P.: Simultaneous improvement in productivity, water use, and albedo through crop structural modification, Glob. Change Biol., 20, 1955-1967, 2014.

Dynamax: Dynagage Sap Flow Sensor User Manual, available at: http://dynamax.com/images/uploads/papers/Dynagage_ Manual.pdf (last access: 29 July 2019), 2007.

Dynamax: Flow32-1K Sap Flow Monitoring System Installation \& Operation Manual, available at: http://www.dynamax.com/ images/uploads/papers/Flow32-1K_Manual.pdf (last access: 21 August 2020), 2017.

Farquhar, G. D. and Roderick, M. L.: Pinatubo, diffuse light, and the carbon cycle, Science, 5615, 1997-1998, 2003.

Farquhar, G. D., von Caemmerer, S., and Berry, J. A.: A biochemical model of photosynthetic $\mathrm{CO}_{2}$ assimilation in leaves of $\mathrm{C}_{3}$ species, Planta, 149, 78-90, 1980. 
Franz, D., Acosta, M., Altimir, N., et al.: Towards long-term standardised carbon and greenhouse gas observations for monitoring Europe's terrestrial ecosystems: a review, Int. Agrophys., 32, 439-455, 2018.

Foken, T.: The energy balance closure problem: an overview, Ecol. Appl., 18, 1351-1367, 2008.

Gao, G., Liu, H., Katul, G. G., and Foken, T.: Non-closure of the surface energy balance explained by phase differences between vertical velocity and scalars of a large atmospheric eddies, Environ. Res. Lett., 12, 034025, https://doi.org/10.1088/17489326/aa625b, 2017.

Goudriaan, J.: A simple and fast numerical method for the computation of daily totals of crop photosynthesis, Agr. Forest Meteorol., 38, 2249-2254, 1986.

Griffis, T. J.: Tracing the flow of carbon dioxide and water vapor between the biosphere and atmosphere: A review of optical isotope techniques and their application, Agr. Forest Meteorol., 174/175, 85-109, 2013.

Gryning, S. E., de Bruin, H., and Batchvarova, E.: Energy balance of a sparse coniferous high-latitude forest, Bound.-Lay. Meteorol., 99, 465-488, 2001.

Hall, F. G., Sellers, P. J., MacPherson, I., Kelly, R. D., Verma, S., Markham, B., Blad, B., Wang, J., and Strebel, D. E.: FIFE: Analysis and results: a review, Adv. Space Res., 9, 275-293, 1989.

Ikawa, H., Chen, C.P., Sikma, M., Yoshimoto, M., Sakai, H., Tokida, T., Usui, Y., Nakamura, H., Ono, K., Maruyama, A., Watanabe, T., Kuwagata, T., and Hasegawa, T.: Increasing canopy photosynthesis in rice can be achieved without a large increase in water use-A model based on free-air $\mathrm{CO}_{2}$ enrichment, Glob. Change Biol. 24, 1321-1341, 2018.

IUSS Working Group WRB: World Reference Base for Soil Resources 2006, FAO Rome: World Soil Resources Reports 103, 145 pp., 2006.

Jacobs, C. M. and de Bruin, H. A.: Predicting regional transpiration at elevated atmospheric $\mathrm{CO}_{2}$ : influence of the PBL-vegetation interaction, J. Appl. Meteorol., 36, 1663-1675, 1997.

Kaiser, E., Morales, A., and Harbinson, J.: Fluctuating Light Takes Crop Photosynthesis on a Rollercoaster Ride, Plant Physiol., 176, 977-989, 2018.

Kanniah, K. D., Beringer, J., North, P., and Hutley, L.: Control of atmospheric particles on diffuse radiation and terrestrial plant productivity: A review, Prog. Phys. Geogr., 2, 209-237, 2012.

Katul, G. G., Oren, R., Manzoni, S., Higgins, C., and Parlange, M. B.: Evapotranspiration: A process driving mass transport and energy exchange in the soil-plant-atmosphere-climate system, Rev. Geophys., 50, RG3002, https://doi.org/10.1029/2011RG000366, 2012.

Jonard, F., De Cannière, S., Brüggemann, N., Gentine, P., Short Gianotti, D. J., Lobet, G., Miralles, D. G., Montzka, C., Pagán, B. R., Rascher, U., and Vereecken, H.: Value of sun-induced chlorophyll fluorescence for quantifying hydrological states and fluxes: current status and challenges, Agr. Forest Meteorol., 291, 108088, https://doi.org/10.1016/j.agrformet.2020.108088, 2020.

Knohl, A. and Baldocchi, D. D.: Effects of diffuse radiation on canopy gas exchange processes in a forest ecosystem, J. Geophys. Res., 113, G02023, https://doi.org/10.1029/2007JG000663, 2008.
Langensiepen, M., Kupisch, M., Graf, A., Schmidt, M., and Ewert, F.: Improving the stem heat balance method for determining sapflow in wheat, Agr. Forest Meteorol., 186, 34-42, 2014.

Lee, X., Griffis, T. J., Baker, J. M., Billmark, K. A., Kim, K., and Welp, L. R.: Canopy-scale kinetic fractionation of atmospheric carbon dioxide and water vapor isotopes, Global Biogeochem. Cy., 23, GB1002, https://doi.org/10.1029/2008GB003331, 2009.

Löhnert, U., Schween, J., Acquistapace, C., Ebell, K., Maahn, M., Barrera-Verdejo, M., Hirsikko, A., Bohn, B., Knaps, A., O' Connor, E. O., Simmer, C., Wahner, A., and Crewell, S.: JOYCE: Jülich Observatory for Cloud Evolution, B. Am. Meteorol. Soc., 96, 1157-1174, 2015.

Lussem, U.: Land use classification of 2018 for the CRC/TR32 measurement region Selhausen/Merken/Merzenhausen, preliminary results, CRC/TR32 Database (TR32DB), https://doi.org/10.5880/TR32DB.32, 2018.

Mauder, M. and Foken, T.: Documentation and instruction manual of the eddy-covariance software package TK3, Internal Report 43, Department of Micrometeorology, University of Bayreuth, Bayreuth, Germany, 60 pp., https://epub.uni-bayreuth.de/342/1/ ARBERG046.pdf (last access: 21 August 2020), 2011.

Mauder, M., Desjardins, R. L., Pattey, E., and Worth, D.: An attempt to close the daytime surface energy balance using spatiallyaveraged flux measurements, Bound.-Lay. Meteorol., 136, 175191, 2010.

Mauder, M., Cuntz, M., Graf, A., Rebmann, C., Schmidt, H., and Steinbrecher, R.: A strategy for quality and uncertainty assessment of eddy-covariance measurements, Agr. Forest Meteorol., 169, 122-135, 2013.

Moene, A. F. and Van Dam, J. C.: Transport in the atmospherevegetation-soil continuum, Cambridge, Cambridge University Press, 436 pp., 2014.

Monson, R. and Baldocchi, D.: Terrestrial Biosphere-Atmosphere Fluxes, Cambridge, Cambridge University Press, 487 pp., 2014.

Nelder, J. A. and Mead, R.: A simple method for function minimization, Comput. J., 4, 308-313, 1965.

Ney, P. and Graf, A.: High-resolution vertical profile measurements for carbon dioxide and water vapour concentrations within and above crop canopies, Bound.-Lay. Meteorol., 166, 449-473, 2018.

Ney, P., Graf, A., Schmidt, M., and Vereecken, H.: The carbon budget of a 4-year crop rotation: using three different non-linear regression $\mathrm{CO}_{2}$ flux partitioning approaches, in preparation, 2020.

Olesen, J., Hansen, P., Berntsen, J., and Christensen, S.: Simulation of above-ground suppression of competing species and competition tolerance in winter wheat varieties, Field Crop. Res., 89, 263-280, 2004.

Pedruzo-Bagazgoitia, X., Ouwersloot, H. G., Sikma, M., van Heerwaarden, C. C., Jacobs, C. M., and Vilà-Guerau de Arellano, J.: Direct and diffuse radiation in the shallow cumulus-vegetation system: enhanced and decreased evapotranspiration regimes, J. Hydrometeorol., 6, 1731-1748, 2017.

Quade, M., Klosterhalfen, A., Graf, A., Brüggemann, N., Hermes, N., Vereecken, H., and Rothfuss, Y.: In-situ monitoring of soil water isotopic composition for partitioning of evapotranspiration during one growing season of sugar beet (Beta vulgaris), Agr. Forest Meteorol., 165, 114-126, 2019.

Rascher, U., Alonso, L., Burkart, A., et al.: Sun-induced fluorescence - a new probe of photosynthesis: First maps from the imag- 
ing spectrometer HyPlant, Glob. Change Biol., 12, 4673-4684, 2015.

Rebmann, C., Aubinet, M., Schmid, H., et al.: ICOS eddy covariance flux-station site setup: a review, Int. Agrophys., 32, 471494, 2018

Reichstein, M., Falge, E., Baldocchi, D., et al.: On the separation of net ecosystem exchange into assimilation and ecosystem respiration. Review and improved algorithm, Glob. Change Biol., 11, 1424-1439, 2005.

Roderick, M. L., Farquhar, G. D., Berry, S. L., and Noble, I. R.: On the direct effect of clouds and atmospheric particles on the productivity and structure of vegetation, Oecologia, 1, 21-30, 2001.

Ronda, R. J., De Bruin, H. A., and Holtslag, A. A.: Representation of the canopy conductance in modeling the surface energy budget for low vegetation, J. Appl. Meteorol., 40, 1431-1444, 2001.

Sakuratani, T.: A heat balance method for measuring water flux in the stem of intact plants, J. Agr. Meteorol., 1, 9-17, 1981.

Santos, E. A., Wagner-Riddle, C., Warland, J., and Brown, S.: Applying a Lagrangian dispersion analysis to infer carbon dioxide and latent heat fluxes in a corn canopy, Agr. Forest Meteorol., 151, 620-632, 2011.

Sellers, P., Hall, F., Margolis, H., Kelly, R., Baldocchi, D., den Hartog, G., Cihlar, J., Ryan, M. G., Goodison, B., Crill, P., Ranson, K. J.,Lettenmaier, D., and Wickland, D. E.: The Boreal Ecosystem-Atmosphere Study (BOREAS): An Overview and Early Results from the 1994 Field Year, B. Am. Meteorol. Soc., 76, 1549-1577, 1995.

Siegmann B., Alonso L., Celesti M., Cogliati S., Colombo R., Damm A., Douglas S., Guanter L., Hanuš J., Kataja K., Kraska T., Matveeva M., Moreno J., Muller O., Pikl M., Pinto F., Quirós Vargas J., Rademske P., Rodriguez-Morene F., Sabater N., Schickling A., Schüttemeyer D., Zemek F., and Rascher U.: The high-performance airborne imaging spectrometer HyPlant From raw images to top-of-canopy reflectance and fluorescence products: Introduction of an automatized processing chain, $\mathrm{Re}-$ mote Sens., 11, 2760, https://doi.org/10.3390/rs11232760, 2019.

Sikma, M., Ouwersloot, H., Pedruzo-Bagazgoitia, X., Van Heerwaarden, C., and Vilà-Guerau de Arellano, J.: Interactions between vegetation, atmospheric turbulence and clouds under a wide range of background wind conditions, Agr. Forest Meteorol., 255, 31-43, 2018.

Sikma, M. Ikawa, H., Heusinkveld, B.G., Yoshimoto, Y., Hasegawa, T., Groot Haar, L. T., Anten., N. P. R., Nakamura, H., VilàGuerau de Arellano, J., Sakai, H., Tokida, T., Usui, Y., and Evers, J. B: Quantifying the feedback between rice architecture, physiology and microclimate under current and future $\mathrm{CO}_{2}$ conditions, J. Geophys. Res.-Biogeo., 125, e2019JG005452, https://doi.org/10.1029/2019JG005452, 2020. van Diepen, K. and Moene A.F.: Canopy photosynthesis under clear and cloud conditions, MSc thesis at Meteorology and Air Quality, Wageningen University, 39 pp., 2019.

van Heerwaarden, C. C. and Teuling, A. J.: Disentangling the response of forest and grassland energy exchange to heatwaves under idealized land-atmosphere coupling, Biogeosciences, 11 6159-6171, https://doi.org/10.5194/bg-11-6159-2014, 2014.

van Heerwaarden, C. C., Vilà-Guerau de Arellano, J., Gounou, A., Guichard, F., and Couvreux, F.: Understanding the daily cycle of evapotranspiration: A method to quantify the influence of forcings and feedbacks, J. Hydrometeorol., 11, 1405-1422, 2010.

van Kesteren, B., Hartogensis, O. K., van Dinther, D., Moene, A.F., De Bruin, H. A., and Holtslag, A. A.: Measuring $\mathrm{H}_{2} \mathrm{O}$ and $\mathrm{CO}_{2}$ fluxes at field scales with scintillometry: Part II-Validation and application of 1-min flux estimates, Agr. Forest Meteorol., 178, 88-105, 2013.

Vico, G., Manzoni, S., Palmroth, S., and Katul, G.: Effects of stomatal delays on the economics of leaf gas exchange under intermittent light regimes, New Phytol., 192, 640-652, 2011.

Vilà-Guerau de Arellano, J., Ouwersloot H. G., Baldocchi D., and Jacobs C. M. J.: Shallow cumulus rooted in photosynthesis, Geophys. Res. Lett., 41, 1796-1802, 2014.

Vilà-Guerau de Arellano, J., van Heerwaarden, C. C., Van Stratum, B. J., and Van den Dries, K.: Atmospheric boundary layer: Integrating air chemistry and land interactions, Cambridge, Cambridge University Press, 279 pp., 2015.

Vilà-Guerau de Arellano, J., Koren, G., Ouwersloot, H. G., van der Velde, I., Röckmann, T., and Miller, J. B.: Sub-diurnal variability of the carbon dioxide and water vapor isotopologues at the field observational scale, Agr. Forest Meteorol., 275, 114-135, 2019.

Warland, J. S. and Thurtell, G. W.: A Lagrangian solution to the relationship between a distributed source and concentration profile, Bound.-Lay. Meteorol., 96, 453-471, 2000.

Wohlfahrt, G., Gerdel, K., Migliavacca, M., Rotenberg, E., Tatarinov, F., J. Müller, J., Hammerle, A., Julitta, T., Spielmann F. M., and Yakir D.: Sun-induced fluorescence and gross primary productivity during a heat wave, Sci. Rep., 8, 14169, https://doi.org/10.1038/s41598-018-32602-z, 2018.

Wutzler, T., Lucas-Moffat, A., Migliavacca, M., Knauer, J., Sickel, K., Šigut, L., Menzer, O., and Reichstein, M. Basic and extensible post-processing of eddy covariance flux data with REddyProc, Biogeosciences, 15, 5015-5030, https://doi.org/10.5194/bg-15-5015-2018, 2018. 